\title{
Design, synthesis and antimicrobial evaluation of some novel quinoline derivatives
}

\begin{abstract}
In an attempt to find new bio-active antimicrobial molecules, a series of quinoline3-carbonitrile and 2-chloroquinoline derivatives were synthesized by multistep reactions. The new compounds were characterized by IR, $1 \mathrm{H}$ NMR and mass spectra. Antimicrobial screening of title compounds (3-24) was carried out against Grampositive and Gram negative bacteria and fungi using agar diffusion technique. To understand the interaction of binding sites with bacterial protein receptor, the docking study was performed using topoisomerase II DNA gyrase enzymes. The newly synthesized compounds 14, 10 and 22 showed significant potency against different bcterial strains compared with Ciprofloxacine, Ampicillin and Gentamicin. While compounds 14, 22 and 6 had strong antifungal activity comparable to Amphotericin B. The results of in vitro antimicrobial activity and docking study revealed that the synthesized compounds have potential antimicrobial activity and can be further optimized and developed as a lead compound.
\end{abstract}

Keywords: quinoline, antimicrobial, vilsmeier-hack, chalcone, docking
Volume 2 Issue 5 - 2015

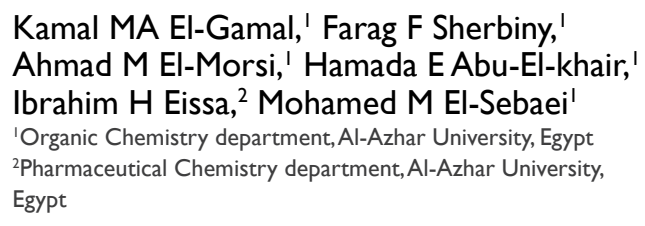

Correspondence: Kamal MA El-Gamal, Organic Chemistry department, Faculty of Pharmacy (Boys), Al-Azhar University, Cairo, I I884,Egypt, Email dr_elseba3y80@yahoo.com

Received: October 20, 2015 | Published: October 24, 2015

\section{Introduction}

\section{Background}

The Global Burden of Disease Study(GBDS) estimates that infectious diseases were responsible for $22 \%$ of all deaths and $27 \%$ of disability-adjusted life years $\left(\mathrm{DALY}_{\mathrm{S}}\right)$ worldwide according to WHO. ${ }^{1}$ Antimicrobial resistance among clinically important bacteria is widely acknowledged as a major global public health threat. ${ }^{2}$ Most of the currently used antimicrobial drugs are associated with adverse effects, such as hepatotoxicity and hypersensitivity. ${ }^{3,4}$ The widespread distribution of infectious diseases, the presence of antimicrobial resistance and the increased side effect of the antimicrobial drugs enhance temptation to design new more effective, safe and economic drugs to treat such infectious diseases and make the field of antimicrobial drug discovery to be of high priority.

The discovery and development of antimicrobial agents provided many classes of compounds. Among them, quinoline derivatives are still an important class of therapeutically useful antimicrobial drugs that control infectious diseases including tuberculosis..$^{5-7}$ It is wellknown that the quinoline nucleus and its derivatives play a vital role in the search on wide antimicrobial activity spectrum. Structure-activity relationship (SAR) studies revealed that the antimicrobial activity in this heterocyclic class of quinoline molecules depends on the nature of the peripheral substituent's and their spatial relationship within the quinoline skeleton. ${ }^{8}$ Moreover, several new pyrazole, ${ }^{9}$ isoxazole, ${ }^{10}$ pyrimidine,${ }^{11}$ guanidine, ${ }^{12}$ nicotinonitrile, ${ }^{13}$ thiazole, ${ }^{14}$ imidazole, ${ }^{15}$ hydrazone, ${ }^{16}$ piperazine,${ }^{17}$ nitrile ${ }^{18}$ and morpholine ${ }^{19}$ moieties were reported to possess antimicrobial activity.

\section{Rationale of molecular design}

In fact, introducing chloroquine into treatment of malaria more than 60 years ago triggered a new era of quickly developing antimicrobial drugs through nalidixic acid and fluoroquinolones with potent activity against a wide spectrum of significant bacterial pathogens such as norfloxacin, and ciprofloxacin ${ }^{19}$ (Figure 1). Depending on ligand based drug design particularly a molecular hybridization approach that involves the coupling of two or more groups with relevant biological properties,$^{20}$ it was decided to select compounds nalidixic, norfloxacin, and ciprofloxacin as lead compounds.

The design and synthesis of the titled compounds were carried out with two objectives: the first was: the synthesis of quinoline nucleus with peripheral substituents at 2 and 3 position (comp. 3\&5). The second objective was: the chemical modification of the synthesized compounds by molecular hybridization of quinoline nucleus with other effective antimicrobial moieties such as pyrazole, isoxazole, pyrimidine, guanidine, nicotinonitrile, thiazole, imidazole, hydrazone, piperazine, and morpholine. This modification afforded two types of new scaffolds. The first type consisted from quinoline nucleus and heterocyclic tail separated by open chain bridge (compounds 8 -17). The second one consisted from quinoline nucleus and nonheterocyclic tail separated by heterocyclic bridge (compounds 18-24).

This approach may allow the construction of new quinoline hybrids with antimicrobial properties with different chemical isosters in order to study the SAR of these compounds and the effect of each substituent on their antimicrobial activity. In addition, we hope to get new, potent, safe and effective antimicrobial agents with lower side effects. 


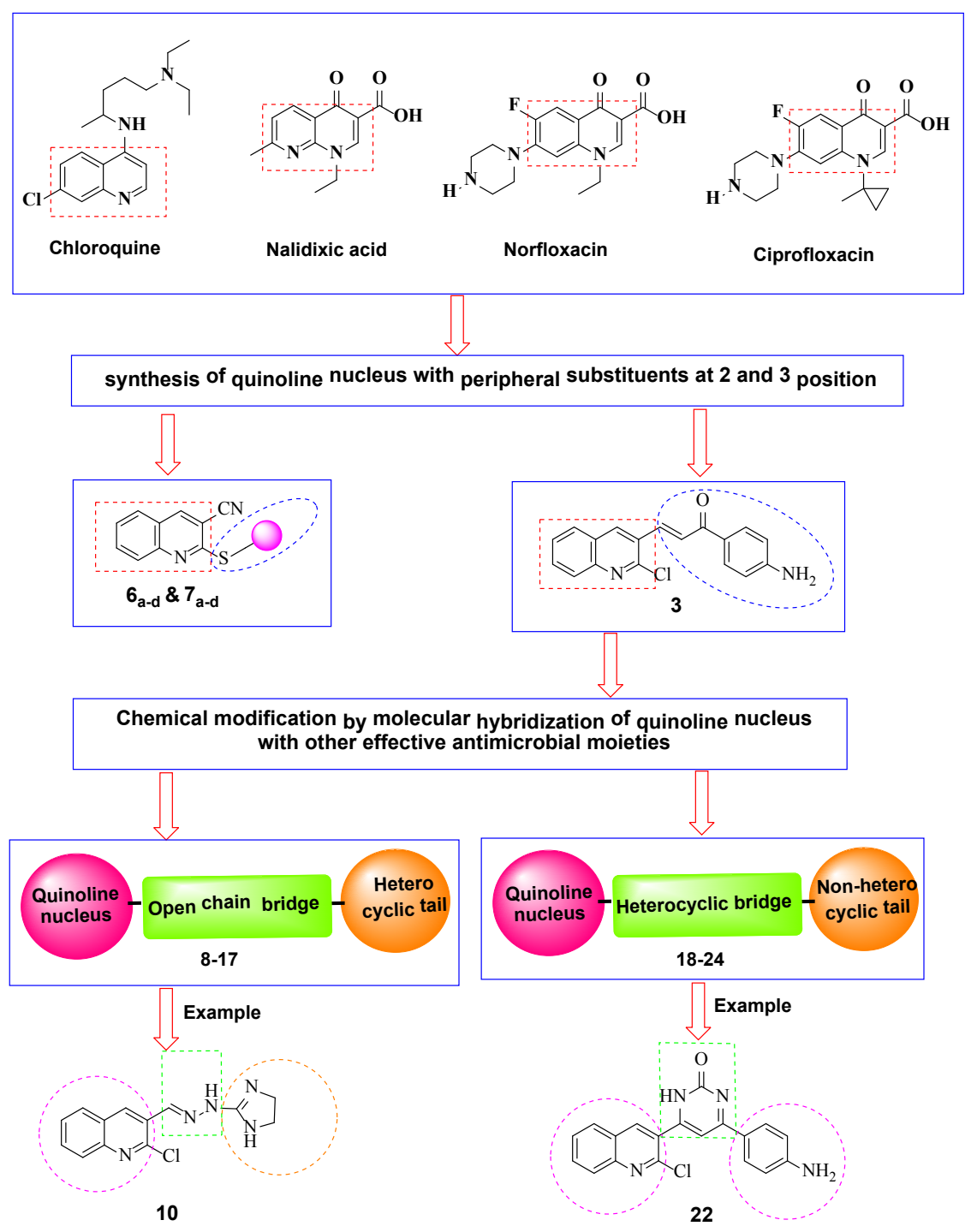

Figure I Rational of design of new anitmicobial agents and chemical modifications

\section{Materials and methods}

\section{Molecular modeling}

Docking was carried out on bacterial type IIA topoisomerase protein downloaded from protein data bank (PDB), (code 4BUL, resolution $2.6 \AA$ ), using discovery studio 2.5 software. The $3 \mathrm{D}$ crystal structure of topoisomerase receptor (code 4BUL) was downloaded from PDB, water molecules were removed. Crystallographic disorders and unfilled valence atoms were corrected using alternate conformations and valence monitor options. Protein was subjected to energy minimization and applying of CHARMM (Chemistry at HARvard Macromolecular Mechanics) force fields for charge, and MMFF94 (Merck Molecular force field) force field for partial charge. Inflexibility of structure is obtained by creating fixed atom constraint. The binding site of the protein (4BUL) was defined and prepared for docking. Ciprofloxacin and the designed compounds $2 \mathrm{D}$ structures were sketched using ChemBioDraw Ultra 14.0 and saved in MDL-SDfile format. SDfile opend, 3D structures are protonated and energy minimized by applying CHARMM force fields for charge, and MMFF94 force field for partial charge, then prepared for docking by optimization the parameters. Molecular docking was performed using (CDOCKER) protocol which is an implementation of the CDOCKER algorithm. CDOCKER is a grid-based molecular docking method that employs CHARMM-based molecular dynamics (MD) scheme to dock ligands into a receptor binding site. The receptor is held rigid while the ligands are allowed to flex during the refinement.

\section{Chemistry}

All melting points were carried on Gallen Kamp point apparatus and are uncorrected. The infrared spectra were recorded on BruckerVector-22-F T-IR spectrophotometer using the potassium bromide disc technique. The 1H NMR spectra were recorded or varian-Gemini$300-\mathrm{MHz}$ spectrophotometer using DMSO- $\mathrm{d}_{6}$ as a solvents and TMS as internal reference. The chemical shift values were recorded in $\delta$ ppm downfield the TMS signal. The Mass spectra were recorded on AZH-ph-AR-XO2 Mass spectrometer. Elemental analyses were performed on $\mathrm{CHN}$ analyzer and all compounds were within \pm 0.4 of the theoretical values. All spectral measurements have been performed 
at the Micro analytical Center, Cairo University, Egypt. The reactions were monitored by thin-layer chromatography (TLC) using TLC sheets coated with UV fluorescent silica gel Merck 60 F254 plates and were visualized using UV lamp and different solvents as mobile phases.

$\mathrm{N}$-phenylacetamide $\quad 1(\mathbf{1}),{ }^{21} \quad$ 2-Chloroquinoline-3-carbaldehyde (2), ${ }^{22}$ 2-chloro quinoline-3-carbonitrile(4), ${ }^{22} 2$-mercapto quinoline-3carbonitrile $(\mathbf{5})^{22}$ were obtained according to the reported procedures (schemes 1-3).

\section{I-(4-aminophenyl)-3-(2-chloroquinolin-3-yl)Prop-2- en-I-one (3)}

To a stirred and ice-cooled aqueous solution of sodium hydroxide $(10 \mathrm{mmol}, 50 \% \mathrm{w} / \mathrm{w})$ and absolute methanol $(25 \mathrm{ml}), 2$-chloroquinoline3 -carbadehyde (2) $(1.91 \mathrm{~g}, 10 \mathrm{mmol})$ was added portion wise followed by 4 -aminoacetophenone $(1.35 \mathrm{~g}, 10 \mathrm{mmol})$. The reaction mixture was stirred vigorously for $3 \mathrm{~h}$ while temperature was maintained below $20^{\circ} \mathrm{C}$ until the reaction mixture became thick. The reaction mixture was left in the refrigerator overnight. The formed precipitate was filtered off under vacuum and washed with copious amount of water until the filtrates became neutral to litmus paper, washed with icecold ethanol $(20 \mathrm{ml})$, and then recrystallized from ethanol to afford compound 3 as a yellow solid.Yield: $85 \%$; m.p. $130^{\circ} \mathrm{C}$. IR $(\mathrm{KBr}) \mathrm{cm}$ ${ }^{1}: 3050\left(\mathrm{CH}\right.$ aromatic), $1650(\mathrm{C}=\mathrm{O}) .1 \mathrm{H}$ NMR $\left(\mathrm{DMSO}-d_{6}\right) \delta \mathrm{ppm}$ : $9.21(\mathrm{~s}, 1 \mathrm{H}$, quinoline- $\mathrm{H} 4), 8.12(\mathrm{~d}, 1 \mathrm{H}, J=8 \mathrm{~Hz}$, quinoline- $\mathrm{H} 5), 7.99$ (d, $1 \mathrm{H}, J=8 \mathrm{~Hz}$, quinoline- $\mathrm{H} 8), 7.87(\mathrm{~d}, 2 \mathrm{H} J=6 \mathrm{~Hz}$, phenyl-H2, H6), 7.70 (t, $1 \mathrm{H}, J=8 \mathrm{~Hz}$, quinoline-H7),7.73 (d, 1H, $J=15 \mathrm{~Hz}, \mathrm{CH}$ alkene $\beta$-proton), 7.63 (d, $1 \mathrm{H}, J=15 \mathrm{~Hz}, \mathrm{CH}$ alkene $\alpha$ - proton), 7.45 (t, $1 \mathrm{H}$, $J=9 \mathrm{~Hz}$, quinoline- $\mathrm{H} 7), 6.76\left(\mathrm{~d}, 2 \mathrm{H}, J=9 \mathrm{~Hz}\right.$, phenyl- $\mathrm{H}_{3}, \mathrm{H} 5$ protons $)$, 4.1 (s, 2H, $\mathrm{NH}_{2}, \mathrm{D}_{2} \mathrm{O}$-exchaneable). $\mathrm{MS}(\mathrm{m} / \mathrm{z}): 310\left(\mathrm{C}_{18} \mathrm{H}_{13} \mathrm{ClN}_{2} \mathrm{O}\right.$, $\left.3.7 \%, \mathrm{M}^{+}+2\right), 308\left(\mathrm{C}_{18} \mathrm{H}_{13} \mathrm{ClN}_{2} \mathrm{O}, 1.2 \%, \mathrm{M}^{+}\right), 273\left(\mathrm{C}_{18} \mathrm{H}_{13} \mathrm{~N}_{2} \mathrm{O}\right.$, $78 \%), 188\left(\mathrm{C}_{1} 1 \mathrm{H}{ }_{7} \mathrm{ClN}, 3.8 \%\right), 77\left(\mathrm{C}_{6} \mathrm{H}_{6}, 100 \%\right)$. Anal. Calc. for: $\left(\mathrm{C}_{18} \mathrm{H}_{13} \mathrm{ClN}_{2} \mathrm{O}\right)$ (M.W.=308): C, 70.02; H, 4.24; N, 9.07\%; Found: $\mathrm{C}$, $70.20 ; \mathrm{H}, 4.56 ; \mathrm{N}, 9.03 \%$.

\section{2-(Alkylthio)quinoline-3-carbonitrile (6 $\left.6_{\text {a-d }}\right)$}

General method: A mixture of 2-mercaptoquinoline-3-carbonitrile (5) $(1.86 \mathrm{~g}, 10 \mathrm{mmol})$ and anhydrous sodium acetate $(1.25 \mathrm{~g}, 15 \mathrm{mmol})$ and an appropriate alkyl halide namely, ethyl bromide, butyl bromide, $\mathrm{n}$-decyl bromide and allyl bromide $(10 \mathrm{mmol})$ in ethanol $(30 \mathrm{ml})$ was heated to reflux for $4 \mathrm{~h}$. On cooling, the precipitate product was collected by filtration and recrystallized from ethanol to afford compounds $6_{\mathrm{a}-\mathrm{d}}$ respectively.

\section{2-(Ethylthio) quinoline-3-carbonitrile (6}

White solid. Yield: $83 \%$; m.p. $120^{\circ} \mathrm{C}$. IR $(\mathrm{KBr}) \mathrm{cm}^{-1}: 3070(\mathrm{CH}$ aromatic), 2985 (CH aliphatic), $2210(\mathrm{CN}) .1 \mathrm{H}$ NMR (DMSO-d6) $\delta$ ppm: 8.96 (s, 1H, quinoline-H4), 8.01 (d, $1 \mathrm{H}, J=8 \mathrm{~Hz}$, quinoline-H5), 7.94 (t, $1 \mathrm{H}, J=9 \mathrm{~Hz}$, quinoline-H6), 7.91 (t, $1 \mathrm{H}, J=9 \mathrm{~Hz}$, quinoline-H7), 7.66 (d, $1 \mathrm{H}, J=8 \mathrm{~Hz}$, quinoline- $\mathrm{H} 8), 3.39$ (q, $2 \mathrm{H}, J=7.2 \mathrm{~Hz}, \mathrm{~S}_{-} \mathrm{CH}_{2}$ ), $1.40\left(\mathrm{t}, 3 \mathrm{H}, J=6.75 \mathrm{~Hz}, \mathrm{CH}_{3}\right)$. MS (m/z): $214\left(\mathrm{C}_{12} \mathrm{H}_{10} \mathrm{~N}_{2} \mathrm{~S}, 70.4 \%\right.$, $\left.\mathrm{M}^{+}\right), 180\left(\mathrm{C}_{10} \mathrm{H}_{5} \mathrm{~N}_{2} \mathrm{~S}, 100 \%\right), 153\left(\mathrm{C}_{10} \mathrm{H}_{5} \mathrm{~N}_{2}, 33 \%\right)$. Anal. Calc. for: $\left(\mathrm{C}_{12} \mathrm{H}_{10} \mathrm{~N}_{2} \mathrm{~S}\right)$ (M.W.=214): C, 67.26; H, 4.70; N, 13.07; Found: C, 66.93; H, 4.61; N, 12.95\%.

\section{2-(Butylthio)quinoline-3-carbonitrile $\left(6_{b}\right)$.}

Yellow solid. Yield: $93 \%$; m.p. $185^{\circ} \mathrm{C}$. IR $(\mathrm{KBr}) \mathrm{cm}^{-1}: 3080(\mathrm{CH}$ aromatic), 2954 (CH aliphatic), $2215(\mathrm{CN}) .1 \mathrm{H} \mathrm{NMR} \mathrm{(DMSO-d_{6 } )} \delta$ ppm: 8.94 (s, 1H, quinoline-H4), $8.00(\mathrm{~d}, 1 \mathrm{H}, J=8 \mathrm{~Hz}$, quinoline- $\mathrm{H} 5)$, $7.91(\mathrm{t}, 1 \mathrm{H}, J=9 \mathrm{~Hz}$, quinoline- H6), $7.64(\mathrm{t}, 1 \mathrm{H}, J=9 \mathrm{~Hz}$, quinoline- $\mathrm{H} 7)$, 7.60 (d, $1 \mathrm{H}, J=8 \mathrm{~Hz}$, quinoline- $\mathrm{H} 8), 3.40$ (t, $2 \mathrm{H}, J=5.7 \mathrm{~Hz}, \mathrm{~S}_{-} \mathrm{CH}_{2}$ ), 1.70 (p, 2H, $\left.J=7.2 \mathrm{~Hz}, \mathrm{CH}_{2}\right), 1.48$ (p, 2H, $\left.J=7.5 \mathrm{~Hz}, \mathrm{CH}_{2}\right), 0.97$ (t, $\left.3 \mathrm{H}, J=5.5 \mathrm{~Hz}, \mathrm{CH}_{3}\right)$. MS $(\mathrm{m} / \mathrm{z}): 242\left(\mathrm{C}_{14} \mathrm{H}_{14} \mathrm{~N}_{2} \mathrm{~S}, 22.18 \%, \mathrm{M}^{+}\right), 200$ $\left(\mathrm{C}_{1} 1 \mathrm{H}_{7} \mathrm{~N}_{2} \mathrm{~S}, 92.86 \%\right), 186\left(\mathrm{C}_{10} \mathrm{H}_{5} \mathrm{~N}_{2} \mathrm{~S}, 100 \%\right), 153\left(\mathrm{C}_{10} \mathrm{H}_{5} \mathrm{~N}_{2}, 53 \%\right)$. Anal. Calc. for: $\left(\mathrm{C}_{14} \mathrm{H}_{14} \mathrm{~N}_{2} \mathrm{~S}\right)$ (M.W.=228): $\mathrm{C}, 69.39 ; \mathrm{H}, 5.8 ; \mathrm{N}, 11.57$; Found: C, 69.11; H, 5.4; N, 11.36\%.

\section{2-(Decylthio)quinoline-3-carbonitrile (6 $)$}

Brownish solid. Yield: $82 \%$; m.p. $270{ }^{\circ} \mathrm{C}$. IR $(\mathrm{KBr}) \mathrm{cm}^{-1}: 3050(\mathrm{CH}$ aromatic), 2950 (CH aliphatic), $2200(\mathrm{CN}) .1 \mathrm{H}$ NMR (DMSO- $\left.d_{6}\right) \delta$ ppm: 8.94 (s, $1 \mathrm{H}$, quinoline- $\mathrm{H} 4), 8.00(\mathrm{~d}, 1 \mathrm{H}, J=8 \mathrm{~Hz}$, quinoline- $\mathrm{H} 5)$, $7.90(\mathrm{t}, 1 \mathrm{H}, J=9 \mathrm{~Hz}$, quinoline- $\mathrm{H} 6), 7.88(\mathrm{t}, 1 \mathrm{H}, J=9 \mathrm{~Hz}$, quinoline$\mathrm{H} 7), 7.64$ (d, $1 \mathrm{H}, J=8 \mathrm{~Hz}$, quinoline- $8 \mathrm{H}), 3.39$ (t, $2 \mathrm{H}, J=6.75 \mathrm{~Hz}$, $\mathrm{S}-\mathrm{CH}_{2}$ ), 1.73 (p, $\left.2 \mathrm{H}, J=6.70 \mathrm{~Hz}, \mathrm{CH}_{2}\right), 1.46$ (p, $2 \mathrm{H}, J=6.50 \mathrm{~Hz}, \mathrm{CH}_{2}$ ), $1.22\left(\mathrm{~s}, 10 \mathrm{H}, J=5.5 \mathrm{~Hz}, \mathrm{CH}_{2}\right), 0.83\left(\mathrm{t}, 3 \mathrm{H}, J=6.75 \mathrm{~Hz}, \mathrm{CH}_{3}\right) . \mathrm{MS}$ $(\mathrm{m} / \mathrm{z}): 326\left(\mathrm{C}_{20} \mathrm{H}_{26} \mathrm{~N}_{2} \mathrm{~S}, 18.76 \%, \mathrm{M}^{+}\right), 199\left(\mathrm{C}_{1} 1 \mathrm{H}_{7} \mathrm{~N}_{2} \mathrm{~S}, 78.86 \%\right), 185$ $\left(\mathrm{C}_{10} \mathrm{H}_{5} \mathrm{~N}_{2} \mathrm{~S}, 100 \%\right), 153\left(\mathrm{C}_{10} \mathrm{H}_{5} \mathrm{~N}_{2}, 25 \%\right)$. Anal. Calc. for: $\left(\mathrm{C}_{19} \mathrm{H}_{24} \mathrm{~N}_{2} \mathrm{~S}\right)$ (M.W.=312): C, 73.57; H, 8.03; N, 8.58; Found: C, 73.11; H, 7.94; $\mathrm{N}, 8.26 \%$.

\section{2-(Allylthio)quinoline-3-carbonitrile $\left(6_{d}\right)$}

White solid. Yield: $90 \%$; m.p. $185^{\circ} \mathrm{C}$. IR $(\mathrm{KBr}) \mathrm{cm}^{-1}: 3075(\mathrm{CH}$ aromatic), 2985 (CH aliphatic), $2210(\mathrm{CN}) .1 \mathrm{H}$ NMR (DMSO- $\left.d_{6}\right) \delta$ ppm: 8.97 (s, $1 \mathrm{H}$, quinoline- $\mathrm{H} 4), 8.02(\mathrm{~d}, 1 \mathrm{H}, J=8 \mathrm{~Hz}$, quinoline- $\mathrm{H} 5)$, $7.92(\mathrm{t}, 1 \mathrm{H}, J=9 \mathrm{~Hz}$, quinoline- $\mathrm{H} 6), 7.68(\mathrm{t}, 1 \mathrm{H}, J=9 \mathrm{~Hz}$, quinolineH7), 7.65 (d, $1 \mathrm{H}, J=8 \mathrm{~Hz}$, quinoline- $\mathrm{H} 8), 6.02$ (q, $1 \mathrm{H}, J=1.8 \mathrm{~Hz}, \mathrm{CH}$ alkene), 5.46 (dd, $1 \mathrm{H}, J=17,1.8 \mathrm{~Hz}, \mathrm{CH}$ alkene trans $\mathrm{H}$ ), 5.15 (dd, $1 \mathrm{H}, J=10,1.8 \mathrm{~Hz}, \mathrm{CH}$ alkene cis $\mathrm{H}), 4.07$ (d, $\left.2 \mathrm{H}, J=6.2 \mathrm{~Hz}, \mathrm{~S}_{-} \mathrm{CH}_{2}\right)$. $\operatorname{MS}(m / z): 226\left(\mathrm{C}_{13} \mathrm{H}_{10} \mathrm{~N}_{2} \mathrm{~S}, 48.96 \%, \mathrm{M}^{+}\right), 214\left(\mathrm{C}_{12} \mathrm{H}_{10} \mathrm{~N}_{2} \mathrm{~S}, 100 \%\right), 199$ $\left(\mathrm{C}_{1} 1 \mathrm{H}_{7} \mathrm{~N}_{2} \mathrm{~S}, 14.29 \%\right)$. Anal. Calc. for: $\left(\mathrm{C}_{13} \mathrm{H}_{10} \mathrm{~N}_{2} \mathrm{~S}\right)(\mathrm{M} . \mathrm{W} .=226)$ : C, 69.00; H, 4.45; N, 12.38; Found: C, 68.93; H, 4.41; N, 11.99\%.

\section{N-(Substituted phenyl) -2-[(3-Cyanoquinolin-2-yl) thio] acetamide $\left(\mathbf{7}_{\mathrm{a}-\mathrm{d}}\right)$}

General method: A mixture of 2-mercaptoquinoline-3-carbonitrile (5) $(1.86 \mathrm{~g}, 10 \mathrm{mmol})$, anhydrous sodium acetate $(1.25 \mathrm{~g}, 15 \mathrm{mmol})$, and the appropriate chloroacetanilides namely, 4-chloro acetanilide, 2-chloro acetanilide, 4-methyl acetanilide and 4-methoxy acetanilide $(10 \mathrm{mmol})$ in absolute ethanol $(30 \mathrm{ml})$ was heated under reflux for $4 \mathrm{~h}$. The reaction mixture was cooled to room temperature. The formed precipitate was collected and recrystallized from absolute ethanol to afford compounds $7_{\mathrm{a}-\mathrm{d}}$ respectively

\section{$\mathrm{N}$-(4-Chlorophenyl)-2-[(3-cyanoquinolin-2-yl)thio] acetamide $\left(7_{\mathrm{a}}\right)$}

Yellowish white solid: Yield: $85 \%$; m.p. $235^{\circ} \mathrm{C}$. IR $(\mathrm{KBr}) \mathrm{cm}^{-1}$ : $3295(\mathrm{NH}), 3080(\mathrm{CH}$ aromatic), 2900 (CH aliphatic), $2222(\mathrm{CN})$, $1675(\mathrm{C}=\mathrm{O}) .1 \mathrm{H}$ NMR $\left(\mathrm{DMSO}-d_{6}\right) \delta \mathrm{ppm}: 10.27\left(\mathrm{~s}, 1 \mathrm{H}, \mathrm{N}-\mathrm{H}, \mathrm{D}_{2} \mathrm{O}-\right.$ exchangeable ), 8.8 (s, $1 \mathrm{H}$, quinoline- $\mathrm{H} 4), 8.01(\mathrm{~d}, 1 \mathrm{H}, J=8 \mathrm{~Hz}$, quinoline- H5), $7.94(\mathrm{t}, 1 \mathrm{H}, J=9 \mathrm{~Hz}$, quinoline- $\mathrm{H} 7), 7.91(\mathrm{t}, 1 \mathrm{H}$, $J=9 \mathrm{~Hz}$, quinoline-H6), $7.56(\mathrm{~d}, 1 \mathrm{H}, J=8 \mathrm{~Hz}$, quinoline- $\mathrm{H} 8), 7.49$ (d, $2 \mathrm{H}, J=6.9 \mathrm{~Hz}$, phenyl-H2, H6), 7.4 (d, 2H, $J=6.9$, phenyl-H3,H5), $4.25\left(\mathrm{~s}, 2 \mathrm{H}, \mathrm{S}-\mathrm{CH}_{2}\right)$. MS $(\mathrm{m} / \mathrm{z}): 355\left(\mathrm{C}_{18} \mathrm{H}_{12} \mathrm{ClN}_{3} \mathrm{OS}, 0.37 \%, \mathrm{M}^{+}\right.$ $+2), 353\left(\mathrm{C}_{18} \mathrm{H}_{12} \mathrm{ClN}_{3} \mathrm{OS}, 0.9 \%, \mathrm{M}^{+}\right), 228\left(\mathrm{C}_{12} \mathrm{H}_{8} \mathrm{~N}_{2} \mathrm{OS}, 100 \%\right), 229$ $\left(\mathrm{C}_{12} \mathrm{H}_{9} \mathrm{~N}_{2} \mathrm{OS}, 89 \%\right), 199\left(\mathrm{C}_{1} 1 \mathrm{H}{ }_{7} \mathrm{~N}_{2} \mathrm{~S}, 9 \%\right), 153\left(\mathrm{C}_{10} \mathrm{H}_{5} \mathrm{~N}_{2}, 25 \%\right), 75$ $\left(\mathrm{C}_{6} \mathrm{H}_{3}, 8 \%\right)$. Anal. Calc. for: $\left(\mathrm{C}_{18} \mathrm{H}_{12} \mathrm{ClN}_{3} \mathrm{OS}\right)(\mathrm{M} . \mathrm{W} .=353)$ : C, 61.10; H, 3.42; N, 11.88\%; Found: C, 61.47; H, 3.25; N, 11.76\%. 


\section{N-(2-Chlorophenyl)-2-[(3-cyanoquinolin-2-yl)thio] acetamide $\left(\mathbf{7}_{\mathrm{b}}\right)$}

Yellowish white solid. Yield: $80 \%$; m.p. $229^{\circ} \mathrm{C}$. IR $(\mathrm{KBr}) \mathrm{cm}^{-1}$ : $3295(\mathrm{NH}), 3080(\mathrm{CH}$ aromatic), $2900(\mathrm{CH}$ aliphatic), $2222(\mathrm{CN})$, $1675(\mathrm{C}=\mathrm{O}) .1 \mathrm{H}$ NMR (DMSO- $\left.d_{6}\right) \delta \mathrm{ppm}: 10.1\left(\mathrm{~s}, 1 \mathrm{H}, \mathrm{N}-\mathrm{H}, \mathrm{D}_{2} \mathrm{O}-\right.$ exchangeable), 9.15 (s, $1 \mathrm{H}$, quinoline-H4), 7.93 (d, $1 \mathrm{H}, J=8 \mathrm{~Hz}$, quinoline- $\mathrm{H} 5), 7.90(\mathrm{t}, 1 \mathrm{H}, J=9 \mathrm{~Hz}$, quinoline- $\mathrm{H} 7), 7.77(\mathrm{t}, 1 \mathrm{H}$, $J=9 \mathrm{~Hz}$, quinoline-H6), $7.66(\mathrm{~d}, 1 \mathrm{H}, J=8 \mathrm{~Hz}$, quinoline- $\mathrm{H} 8), 7.5-$ 7.2 (m, 4H,aromatic protons), $4.35\left(\mathrm{~s}, 2 \mathrm{H}, \mathrm{S}-\mathrm{CH}_{2}\right) \cdot \mathrm{MS}(\mathrm{m} / \mathrm{z}): 355$ $\left(\mathrm{C}_{18} \mathrm{H}_{12} \mathrm{ClN}_{3} \mathrm{OS}, 0.37 \%, \mathrm{M}^{+}+2\right), 353\left(\mathrm{C}_{18} \mathrm{H}_{12} \mathrm{ClN}_{3} \mathrm{OS}, 0.9 \%, \mathrm{M}^{+}\right), 228$ $\left(\mathrm{C}_{12} \mathrm{H}_{8} \mathrm{~N}_{2} \mathrm{OS}, 100 \%\right), 229\left(\mathrm{C}_{12} \mathrm{H}_{9} \mathrm{~N}_{2} \mathrm{OS}, 89 \%\right), 199\left(\mathrm{C}_{1} 1 \mathrm{H}_{7} \mathrm{~N}_{2} \mathrm{~S}, 9 \%\right)$, $153\left(\mathrm{C}_{10} \mathrm{H}_{5} \mathrm{~N}_{2}, 25 \%\right), 75\left(\mathrm{C}_{6} \mathrm{H}_{3}, 8 \%\right)$. Anal. Calc. for: $\left(\mathrm{C}_{18} \mathrm{H}_{12} \mathrm{ClN}_{3} \mathrm{OS}\right)$ (M.W.=353): C, 61.10; H, 3.42; N, 11.88\%; Found: C, 61.47; H, 3.25; $\mathrm{N}, 11.54 \%$.

\section{N-(4-Methyl phenyl)-2-[(3-cyanoquinolin-2-yl)thio] acetamide $\left(\mathbf{7}_{c}\right)$}

Brown solid. Yield: $85 \%$; m.p. $222^{\circ} \mathrm{C}$. IR $(\mathrm{KBr}) \mathrm{cm}^{-1}: 3300(\mathrm{NH})$, $3122(\mathrm{CH}$ aromatic), 2900 ( $\mathrm{CH}$ aliphatic), $2221(\mathrm{CN}), 1665(\mathrm{C}=\mathrm{O})$. $1 \mathrm{H}$ NMR (DMSO- $\left.d_{6}\right) \delta$ ppm: $10.27\left(\mathrm{~s}, 1 \mathrm{H}, \mathrm{N}-\mathrm{H}, \mathrm{D}_{2} \mathrm{O}\right.$-exchangeable ), $9.10(\mathrm{~s}, 1 \mathrm{H}$, quinoline-H4), $8.01(\mathrm{~d}, 1 \mathrm{H}, J=8 \mathrm{~Hz}$, quinoline- $\mathrm{H} 5), 7.90$ (t, $1 \mathrm{H}, J=9 \mathrm{~Hz}$, quinoline-H7), $7.81(\mathrm{t}, 1 \mathrm{H}, J=9 \mathrm{~Hz}$, quinoline-H6), $7.66(\mathrm{~d}, 1 \mathrm{H}, J=8 \mathrm{~Hz}$, quinoline- $\mathrm{H} 8), 7.6(\mathrm{~d}, 2 \mathrm{H}, J=9 \mathrm{~Hz}$, phenyl-H2, H6), 7.4 (d, 2H, J=6.9, phenyl-H3, H5), 4.2 (s, 2H, S-CH $), 2.6$ (s, $\left.3 \mathrm{H}, \mathrm{CH}_{3}\right)$. MS $(\mathrm{m} / z): 333\left(\mathrm{C}_{19} \mathrm{H}_{15} \mathrm{~N}_{3} \mathrm{OS}, 10.5 \%, \mathrm{M}^{+}\right), 257\left(\mathrm{C}_{12} \mathrm{H}_{8} \mathrm{~N}_{2} \mathrm{OS}\right.$, $100 \%), 229\left(\mathrm{C}_{12} \mathrm{H}_{0} \mathrm{~N}_{2} \mathrm{OS}, 75.7 \%\right), 199\left(\mathrm{C}_{1} 1 \mathrm{H}{ }_{7} \mathrm{~N}_{2} \mathrm{~S}, 9.3 \%\right), 153$ $\left(\mathrm{C}_{10} \mathrm{H}_{5} \mathrm{~N}_{2}, 17.8 \%\right), 75\left(\mathrm{C}_{6} \mathrm{H}_{3}, 1.3 \%\right)$. Anal. Calc. for: $\left(\mathrm{C}_{19} \mathrm{H}_{15} \mathrm{~N}_{3} \mathrm{OS}\right)$ (M.W.=333): C, 68.45; H, 4.53; N, 12.60\%; Found: C, 68.12; H, 4.41; $\mathrm{N}, 12.07 \%$.

\section{-(4-Methoxy phenyl)-2-[(3-cyanoquinolin-2-yl)thio] acetamide $\left(\mathbf{7}_{\mathrm{d}}\right)$}

Grey solid. Yield: $85 \%$; m.p. $230^{\circ} \mathrm{C}$. IR $(\mathrm{KBr}) \mathrm{cm}^{-1}: 3261(\mathrm{NH})$, 3071 (CH aromatic), 2900 ( $\mathrm{CH}$ aliphatic), $2225(\mathrm{CN}), 1666(\mathrm{C}=\mathrm{O})$. $1 \mathrm{H}$ NMR (DMSO- $\left.d_{6}\right) \delta$ ppm: $10.28\left(\mathrm{~s}, 1 \mathrm{H}, \mathrm{N}-\mathrm{H}, \mathrm{D}_{2} \mathrm{O}\right.$-exchangeable ), $9.00(\mathrm{~s}, 1 \mathrm{H}$, quinoline-H4), $8.01(\mathrm{~d}, 1 \mathrm{H}, J=8 \mathrm{~Hz}$, quinoline-H5), 7.90 $(\mathrm{t}, 1 \mathrm{H}, J=9 \mathrm{~Hz}$, quinoline- $\mathrm{H} 7), 7.81(\mathrm{t}, 1 \mathrm{H}, J=8 \mathrm{~Hz}$, quinoline-H6), $7.66(\mathrm{~d}, 1 \mathrm{H}, J=8 \mathrm{~Hz}$, quinoline- $\mathrm{H} 8), 7.60(\mathrm{~d}, 2 \mathrm{H}, J=6.9 \mathrm{~Hz}$, phenyl-H2, H6), 7.4 (d, 2H, J=6.9, phenyl-H3, H5), 4.25 (s, 2H, $\left.\mathrm{S}_{-} \mathrm{CH}_{2}\right), 3.99\left(\mathrm{~s}, 3 \mathrm{H}, \mathrm{OCH}_{3}\right)$. MS $(\mathrm{m} / \mathrm{z}): 349\left(\mathrm{C}_{10} \mathrm{H}_{15} \mathrm{~N}_{3} \mathrm{O}_{2} \mathrm{~S}, 10.5 \%\right.$, $\left.\mathrm{M}^{+}\right), 257\left(\mathrm{C}_{12} \mathrm{H}_{8} \mathrm{~N}_{2} \mathrm{OS}, 100 \%\right), 229\left(\mathrm{C}_{12} \mathrm{H}_{9} \mathrm{~N}_{2} \mathrm{OS}, 75.7 \%\right), 199\left(\mathrm{C}_{1} 1 \mathrm{H}\right.$ $\left.{ }_{7} \mathrm{~N}_{2} \mathrm{~S}, 9.3 \%\right), 153\left(\mathrm{C}_{10} \mathrm{H}_{5} \mathrm{~N}_{2}, 17.8 \%\right), 75\left(\mathrm{C}_{6} \mathrm{H}_{3}, 1.3 \%\right)$. Anal. Calc. for: $\left(\mathrm{C}_{19} \mathrm{H}_{15} \mathrm{~N}_{3} \mathrm{O}_{2} \mathrm{~S}\right)$ (M.W.=349): C, 65.31; H, 4.33; N, 12.03\%; Found: C, $65.02 ; \mathrm{H}, 4.10 ; \mathrm{N}, 11.97 \%$.

\section{General method for synthesis of compounds 8-I 7}

A mixture of 2-Chloroquinoline-3-carbaldehyde (2) (1.91g, $0.01 \mathrm{~mole})$ and glacial acetic acid $(0.5 \mathrm{ml})$. and an appropriate primary amine derivatives namely, 2-amino-3-methylquinazolin-4(3H)-one, 5-amino-1-phenyl-1H -pyrazole-4-ethyl carboxylate, 2-hydrazinyl4,5-dihydro-1H -imidazole hydrobromide, 4-chlorobenzohydrazide, $\mathrm{N}$-(4-aminophenyl)-4-ethylbenzamide, thiazole-2-amine, 2-hydrazinyl acetonitrile, benzo [d] thiazol-2-amine, morpholin-4-amine, 4-methyl piperazin-1-amine. $(0.01 \mathrm{~mole})$ in absolute ethanol $(30 \mathrm{ml})$ was heated to reflux for $22 \mathrm{~h}$. the reaction mixture was cooled and the obtained solid products were filtered off, washed with absolute ethanol $(10 \mathrm{ml})$ and air dried to afford compounds 8-17.

\section{$3-\{[(2-C h l o r o q u i n o l i n-3-y l)$ methylene $]$ amino $\}-2$ - methylquinazolin-4(3H)-one (8)}

Light yellow powder. Yield: 90\%. m.p.: $285{ }^{\circ} \mathrm{C} .1 \mathrm{H}$ NMR (DMSO- $d_{6}$ ) $\delta$ ppm: 9.57 (s, 1H, quinoline-H4), $9.27(\mathrm{~s}, 1 \mathrm{H}, \mathrm{CH}=\mathrm{N})$, $8.30(\mathrm{~d}, 1 \mathrm{H}, J=9 \mathrm{~Hz}$, quinoline- $\mathrm{H} 5$, quinazolin- $\mathrm{H} 5), 8.18(\mathrm{~d}, 1 \mathrm{H}, J=9 \mathrm{~Hz}$, quinoline- $\mathrm{H} 8), 7.95$ ( t, $1 \mathrm{H}, J=9 \mathrm{~Hz}$, quinoline- $\mathrm{H} 7$, quinazolin- $\mathrm{H} 7$ ), $7.75(\mathrm{t}, 1 \mathrm{H}, J=9 \mathrm{~Hz}$, quinoline- $6 \mathrm{H}$, quinazolin- $\mathrm{H} 6), 2.6\left(\mathrm{~s}, 3 \mathrm{H}, \mathrm{CH}_{3}\right)$. MS $(\mathrm{m} / z): 350\left(\mathrm{C}_{19} \mathrm{H}_{13} \mathrm{ClN}_{4} \mathrm{O}, 0.64 \%, \mathrm{M}^{+}+2\right), 348\left(\mathrm{C}_{19} \mathrm{H}_{13} \mathrm{ClN}_{4} \mathrm{O}\right.$, $\left.1.89 \%, \mathrm{M}^{+}\right), 313\left(\mathrm{C}_{19} \mathrm{H}_{13} \mathrm{~N}_{4} \mathrm{O}, 25.13 \%\right), 298\left(\mathrm{C}_{18} \mathrm{H}_{11} \mathrm{~N}_{4} \mathrm{O}, 19.12 \%\right)$, $160\left(\mathrm{C}_{10} \mathrm{H}_{10} \mathrm{~N}_{2}, 100 \%\right)$. Anal. Calc. for: $\left(\mathrm{C}_{19} \mathrm{H}_{13} \mathrm{ClN}_{4} \mathrm{O}\right)(\mathrm{M} . \mathrm{W} .=348)$ : C, 65.43; H, 3.76; N, 16.06; Found: C, 65.23; H, 3.35; N, 15.96\%.

\section{5-\{[(2-Chloroquinolin-3-yl)methylene ]amino $\}$ I - phenyl- I H -pyrazole-4-ethylcarboxyl- ate (9)}

Light yellow powder. Yield: $90 \%$. m.p: $285^{\circ} \mathrm{C}$. IR $(\mathrm{KBr}) \mathrm{cm}^{-1}$. $3122(\mathrm{CH}$ aromatic), 2900 ( $\mathrm{CH}$ aliphatic), $1750(\mathrm{C}=\mathrm{O}), 1665(\mathrm{C}=\mathrm{N})$. $1 \mathrm{H}$ NMR (DMSO-d $)_{6} \delta$ ppm: $9.00(\mathrm{~s}, 1 \mathrm{H}$, quinoline-H4), 8.55 $(\mathrm{s}, 1 \mathrm{H}, \mathrm{CH}=\mathrm{N}), 8.30(\mathrm{~d}, 1 \mathrm{H}, J=9 \mathrm{~Hz}$, quinoline-H5), $8.28(\mathrm{~s}, 1 \mathrm{H}$, pyrazol-H3), 8.14 (d, $1 \mathrm{H}, J=9 \mathrm{~Hz}$, quinoline-H8), 8.10 (d, $2 \mathrm{H}, J=8 \mathrm{~Hz}$, phenyl- H2, H6), 7.98 (t, $1 \mathrm{H}, J=8 \mathrm{~Hz}$, quinoline-7H), 7.86 (t, $1 \mathrm{H}, J=8$, quinoline-H6), 7.7 (m, 3H, phenyl-H3, H4, H5) 4.24 (q, $2 \mathrm{H}, J=6.7 \mathrm{~Hz}$, $\left.\mathrm{O}-\mathrm{CH}_{2}\right), 1.28$ (t, $\left.3 \mathrm{H}, J=6.5 \mathrm{~Hz}, \mathrm{CH}_{3}\right)$. Anal. Calc. for: $\left(\mathrm{C}_{22} \mathrm{H}_{17} \mathrm{ClN}_{4} \mathrm{O}\right)$ (M.W.=404): C, 65.27; H, 4.23; N, 13.84; Found: C, 65.03; H, 3.99; $\mathrm{N}, 13.86 \%$.

\section{2-Chloro-3-\{[2-(4,5-dihydro- I H -imidazol-2-yl) Hydrazono]methyl\} quinoline (10)}

Light yellow powder. Yield: $75 \%$. m.p.: $260^{\circ} \mathrm{C} .1 \mathrm{H}$ NMR $\left(\mathrm{DMSO}-d_{6}\right) \delta \mathrm{ppm}: 12.7\left(\mathrm{~s}, 1 \mathrm{H}, \mathrm{NH}, \mathrm{D}_{2} \mathrm{O}\right.$-exchaneable), $9.22(\mathrm{~s}, 1 \mathrm{H}$, quinoline-H4), $8.96\left(\mathrm{~s}, 1 \mathrm{H}, \mathrm{NH}, \mathrm{D}_{2} \mathrm{O}\right.$-exchangeable), $8.66(\mathrm{~s}, 1 \mathrm{H}$, $\mathrm{CH}=\mathrm{N}), 8.06(\mathrm{~d}, 1 \mathrm{H}, J=8 \mathrm{~Hz}$, quinoline-H5), $7.97(\mathrm{~d}, 1 \mathrm{H}, J=8 \mathrm{~Hz}$, quinoline-H8), $7.87(\mathrm{t}, 1 \mathrm{H}, J=9 \mathrm{~Hz}$, quinoline-H7), $7.77(\mathrm{t}, 1 \mathrm{H}$, $J=9 \mathrm{~Hz}$, quinoline-H6), $3.8\left(\mathrm{~s}, 4 \mathrm{H}, 2 \mathrm{CH}_{2}\right)$. MS $(\mathrm{m} / \mathrm{z}): 275\left(\mathrm{C}_{13} \mathrm{H}_{12} \mathrm{ClN}_{5}\right.$, $\left.1.64 \%, \mathrm{M}^{+}+2\right), 273\left(\mathrm{C}_{13} \mathrm{H}_{12} \mathrm{ClN}_{5}, 4.86 \%, \mathrm{M}^{+}\right), 238\left(\mathrm{C}_{13} \mathrm{H}_{12} \mathrm{~N}_{5}, 51.2 \%\right)$, $200\left(\mathrm{C}_{10} \mathrm{H}_{5} \mathrm{~N}_{3} \mathrm{Cl}, 73.66 \%\right), 185.99\left(\mathrm{C}_{10} \mathrm{H}_{5} \mathrm{~N}_{2} \mathrm{Cl}, 100 \%\right)$. Anal. Calc. for: $\left(\mathrm{C}_{13} \mathrm{H}_{12} \mathrm{ClN}_{5}\right)(\mathrm{M} . \mathrm{W} .=273): \mathrm{C}, 57.02 ; \mathrm{H}, 4.42 ; \mathrm{N}, 25.59 \%$; Found: $\mathrm{C}$, 57.37; H, 4.19; N, 25.43\%.

\section{4-Chloro-N-[(2-chloroquinolin-3-yl)methylene] benzohydrazide (I I)}

Light yellow powder. Yield: $70 \%$. m.p.: $270^{\circ} \mathrm{C} .1 \mathrm{H}$ NMR(DMSO- $\left.d_{6}\right) \delta$ ppm: 12.32 (s, $1 \mathrm{H}, \mathrm{OH}, \mathrm{D}_{2} \mathrm{O}$-exchaneable), 10.62 (s, 1H, NH, $\mathrm{D}_{2} \mathrm{O}$-exchaneable), $8.97(\mathrm{~s}, 1 \mathrm{H}$, quinoline-H4), $8.22(\mathrm{~s}$, $1 \mathrm{H}, \mathrm{CH}=\mathrm{N}), 8.01(\mathrm{~d}, 1 \mathrm{H}, J=8 \mathrm{~Hz}$, quinoline-H5), $7.99(\mathrm{~d}, 1 \mathrm{H}, J=8 \mathrm{~Hz}$, quinoline-H8), 7.94(d, 2H, $J=6 \mathrm{~Hz}$, phenyl-H2, H6), 7.87 (t, $1 \mathrm{H}$, $J=8 \mathrm{~Hz}$, quinoline- $\mathrm{H} 7), 7.69(\mathrm{t}, 1 \mathrm{H}, J=8 \mathrm{~Hz}$, quinoline- $\mathrm{H} 6), 7.62(\mathrm{~d}$, $2 \mathrm{H}, J=6 \mathrm{~Hz}$, phenyl-H3, H5). MS $(\mathrm{m} / \mathrm{z}): 345\left(\mathrm{C}_{17} \mathrm{H}_{11} \mathrm{Cl}_{2} \mathrm{~N}_{3} \mathrm{O}, 1.54 \%\right.$, $\left.\mathrm{M}^{+}+2\right), 343\left(\mathrm{C}_{17} \mathrm{H}_{11} \mathrm{Cl}_{2} \mathrm{~N}_{3} \mathrm{O}, 2.37 \%, \mathrm{M}^{+}\right), 308\left(\mathrm{C}_{17} \mathrm{H}_{11} \mathrm{ClN}_{3}, 7.08 \%\right)$, $189\left(\mathrm{C}_{10} \mathrm{H}_{6} \mathrm{ClN}_{2}, 100 \%\right)$. Anal. Calc. for: $\left(\mathrm{C}_{17} \mathrm{H}_{11} \mathrm{Cl}_{2} \mathrm{~N}_{3}\right)$ (M.W. $\left.=343\right)$ : C, 59.32; H, 3.22; N, 12.21\%; Found: C, 59.31; H, 3.19; N, 12.43\%.

\section{$\{[(2-C h l o r o q u i n o l i n-3-y l)$ methylene)amino $]$ Phenyl $\}$ - 4ethy]benzamide( 12 )}

Light yellow powder. Yield: $65 \%$. m.p.: $290{ }^{\circ} \mathrm{C} .1 \mathrm{H}$ NMR $\left(\right.$ DMSO- $\left.d_{6}\right) \delta$ ppm: $10.38\left(\mathrm{~s}, 1 \mathrm{H}, \mathrm{NH}, \mathrm{D}_{2} \mathrm{O}-\right.$ exchaneable $), 9.04$ (s, $1 \mathrm{H}$, quinoline-H4), $8.88(\mathrm{~s}, 1 \mathrm{H}, \mathrm{CH}=\mathrm{N}), 8.14(\mathrm{~d}, 1 \mathrm{H}, J=8 \mathrm{~Hz}$, quinoline-H5), $7.99(\mathrm{~d}, 1 \mathrm{H}, J=8 \mathrm{~Hz}$, quinoline-H8), 7.93(d, $1 \mathrm{H}$, $J=6 \mathrm{~Hz}$, phenyl-H2, H6), 7.87 (t, $1 \mathrm{H}, J=8 \mathrm{~Hz}$, quinoline-H7), 7.69 
(t, $1 \mathrm{H}, J=9 \mathrm{~Hz}$, quinoline-H6), 7.62 (d, $2 \mathrm{H}, J=6 \mathrm{~Hz}$, phenyl-H3, H5), 2.8 (q, 2H, $\left.J=6.7 \mathrm{~Hz}, \mathrm{CH}_{2}\right), 1.2\left(\mathrm{t}, 3 \mathrm{H}, J=6.5 \mathrm{~Hz},-\mathrm{CH}_{3}\right) . \mathbf{M S}(\mathrm{m} / \mathrm{z})$ $415\left(\mathrm{C}_{25} \mathrm{H}_{20} \mathrm{ClN}_{3} \mathrm{O}, 1.24 \%, \mathrm{M}^{+}+2\right), 413\left(\mathrm{C}_{25} \mathrm{H}_{20} \mathrm{ClN}_{3} \mathrm{O}, 3.72 \%, \mathrm{M}^{+}\right)$, $378\left(\mathrm{C}_{25} \mathrm{H}_{20} \mathrm{~N}_{3} \mathrm{O}, 22.2 \%\right), 189\left(\mathrm{C}_{10} \mathrm{H}_{6} \mathrm{ClN}_{2}, 100 \%\right)$. Anal. Calc. for: $\left(\mathrm{C}_{25} \mathrm{H}_{20} \mathrm{ClN}_{3} \mathrm{O}\right)(\mathrm{M} . \mathrm{W} .=413): \mathrm{C}, 72.55 ; \mathrm{H}, 4.87 ; \mathrm{N}, 10.15 \%$; Found: $\mathrm{C}$, $72.31 ; \mathrm{H}, 4.89 ; \mathrm{N}, 10.43 \%$.

\section{I - (2 - Chloroquinolin-3-yI)-N-(thiazol-2-yl) methanimine (13)}

Light yellow powder. Yield: $65 \%$. m.p.: $210^{\circ} \mathrm{C} .1 \mathrm{H}$ NMR $\left(\mathrm{DMSO}-d_{6}\right) \delta \mathrm{ppm}: 9.04(\mathrm{~s}, 1 \mathrm{H}$, quinoline-H4), $8.88(\mathrm{~s}, 1 \mathrm{H}$ $\mathrm{CH}=\mathrm{N}), 8.14$ (d, $1 \mathrm{H}, J=8 \mathrm{~Hz}$, quinoline-H5), 7.99 (d, $1 \mathrm{H}, J=8 \mathrm{~Hz}$, quinoline-H8), 7.87 (t, $1 \mathrm{H}, J=9 \mathrm{~Hz}$, quinoline-H7), 7.69 (t, $1 \mathrm{H}$, $J=9 \mathrm{~Hz}$, quinoline-H6), $7.62(\mathrm{~d}, 2 \mathrm{H}, J=6 \mathrm{~Hz}$, thiazol-H2,H3). MS $(\mathrm{m} / z): 275\left(\mathrm{C}_{13} \mathrm{H}_{8} \mathrm{ClN}_{3} \mathrm{~S}, 1.16 \%, \mathrm{M}^{+}+2\right), 273\left(\mathrm{C}_{13} \mathrm{H}_{8} \mathrm{ClN}_{3} \mathrm{~S}, 4.51 \%\right.$, $\left.\mathrm{M}^{+}\right), 238\left(\mathrm{C}_{13} \mathrm{H}_{8} \mathrm{~N}_{3} \mathrm{~S}, 12.2 \%\right), 189\left(\mathrm{C}_{10} \mathrm{H}_{6} \mathrm{ClN}_{2}, 100 \%\right)$. Anal. Calc. for: $\left(\mathrm{C}_{13} \mathrm{H}_{8} \mathrm{ClN}_{3} \mathrm{~S}\right)$ (M.W.=273): C, 57.04; H, 2.95; N, 15.35\%; Found: $\mathrm{C}$, $57.31 ; \mathrm{H}, 2.89 ; \mathrm{N}, 15.43 \%$.

\section{2-\{2-[(2-Chloroquinolin-3-yl)methylene]hydrazinyl $\}$ acetonitrile (14)}

Light brown powder. Yield: $65 \%$. m.p.: $135^{\circ} \mathrm{C} . \mathrm{IR}(\mathrm{KBr}) \mathrm{cm}^{-1}$ : $3295(\mathrm{NH}), 3080(\mathrm{CH}$, aromatic), $2900(\mathrm{CH}$ aliphatic), $2222(\mathrm{CN})$ $1 \mathrm{H}$ NMR (DMSO- $\left.d_{6}\right) \delta$ ppm: $9.2(\mathrm{~s}, 1 \mathrm{H}$, quinoline-H4), $8.97(\mathrm{~s}, 1 \mathrm{H}$, $\mathrm{CH}=\mathrm{N}), 8.44(\mathrm{~d}, 1 \mathrm{H}, J=8 \mathrm{~Hz}$, quinoline-H5), $8.01(\mathrm{~d}, 1 \mathrm{H}, J=8 \mathrm{~Hz}$, quinoline-H8), $7.83(\mathrm{t}, 1 \mathrm{H}, J=9 \mathrm{~Hz}$, quinoline-H7), $7.67(\mathrm{t}, 1 \mathrm{H}, J=9 \mathrm{~Hz}$, quinoline-H6), $7.2\left(\mathrm{~s}, 1 \mathrm{H}, \mathrm{NH}, \mathrm{D}_{2} \mathrm{O}\right.$-exchaneable), $4.2\left(\mathrm{~s}, 2 \mathrm{H},-\mathrm{CH}_{2}\right)$ MS (m/z): $246\left(\mathrm{C}_{12} \mathrm{H}_{9} \mathrm{ClN}_{4}, 2.43 \%, \mathrm{M}^{+}+2\right), 244\left(\mathrm{C}_{12} \mathrm{H}_{9} \mathrm{ClN}_{4}, 7.18 \%\right.$, $\left.\mathrm{M}^{+}\right), 209\left(\mathrm{C}_{12} \mathrm{H}_{9} \mathrm{~N}_{4}, 29.2 \%\right), 189\left(\mathrm{C}_{10} \mathrm{H}_{6} \mathrm{ClN}_{2}, 100 \%\right)$. Anal. Calc. for: $\left(\mathrm{C}_{12} \mathrm{H}_{9} \mathrm{ClN}_{4}\right)(\mathrm{M} . \mathrm{W} .=244): \mathrm{C}, 58.90 ; \mathrm{H}, 3.71 ; \mathrm{N}, 22.90 \%$; Found: $\mathrm{C}$ $58.41 ; \mathrm{H}, 3.89 ; \mathrm{N}, 22.43 \%$

\section{N-(Benzo[d]thiazol-2-yl)- I-(2-chloroquinolin-3-yl) methanimine (I5)}

light red powder. Yield: 59\%. m.p: $190^{\circ} \mathrm{C} .1 \mathrm{H} \mathrm{NMR}\left(\mathrm{DMSO}-d_{6}\right)$ $\delta$ ppm: $9.05(\mathrm{~s}, 1 \mathrm{H}$, quinoline- $\mathrm{H} 4),, 8.86(\mathrm{~s}, 1 \mathrm{H}, \mathrm{CH}=\mathrm{N}), 8.53(\mathrm{~d}, 1 \mathrm{H}$, $J=8 \mathrm{~Hz}$, benzothiazol-H4), 7.99 (d, $1 \mathrm{H}, J=8 \mathrm{~Hz}$, quinoline-H8), 7.95 (d, $1 \mathrm{H}, J=8 \mathrm{~Hz}$, benzothiazol-H7), $7.76(\mathrm{t}, 1 \mathrm{H}, J=8 \mathrm{~Hz}$, quinolin- $\mathrm{H} 7$ ), 7.70 (t, $1 \mathrm{H}, J=8 \mathrm{~Hz}$, quinolin- $\mathrm{H} 6), 7.5(\mathrm{~d}, 2 \mathrm{H}, J=6.8 \mathrm{~Hz}$, benzothiazolH5,H6). MS $(m / z): 325 \quad\left(\mathrm{C}_{17} \mathrm{H}_{10} \mathrm{ClN}_{3} \mathrm{~S}, \quad 2.66 \%, \quad \mathbf{M}^{+}+2\right), 323$ $\left(\mathrm{C}_{17} \mathrm{H}_{10} \mathrm{ClN}_{3} \mathrm{~S}, 7.66 \%, \mathrm{M}^{+}\right), 288\left(\mathrm{C}_{17} \mathrm{H}_{10} \mathrm{~N}_{3} \mathrm{~S}, 32.2 \%\right), 177\left(\mathrm{C}_{10} \mathrm{H}_{8} \mathrm{ClN}\right.$, $100 \%)$. Anal.Calc. for: $\left(\mathrm{C}_{17} \mathrm{H}_{10} \mathrm{ClN}_{3} \mathrm{~S}\right)(\mathrm{M} . \mathrm{W} .=323)$ : $\mathrm{C}, 63.06 ; \mathrm{H}, 3.11$; N, 12.98\%; Found: C, 63.31; H, 2.99; N, 12.73\%.

\section{I-(2-Chloroquinolin-3yl)-N-morpholinomethanimine (16)}

Brown powder. Yield: $75 \%$. m.p.: $105{ }^{\circ} \mathrm{C} .1 \mathrm{H}$ NMR (DMSO-d6) $\delta$ ppm: $9.2(\mathrm{~s}, 1 \mathrm{H}$, quinoline-H4), $8.5(\mathrm{~s}, 1 \mathrm{H}, \mathrm{CH}=\mathrm{N}), 8.44(\mathrm{~d}, 1 \mathrm{H}$, $J=8 \mathrm{~Hz}$, quinoline- $\mathrm{H} 5), 8.01(\mathrm{~d}, 1 \mathrm{H}, J=8 \mathrm{~Hz}$, quinoline- $\mathrm{H} 8), 7.83(\mathrm{t}, 1 \mathrm{H}$, $J=8 \mathrm{~Hz}$, quinoline-H7), $7.67(\mathrm{t}, 1 \mathrm{H}, J=8 \mathrm{~Hz}$, quinoline-H6). $3.75(\mathrm{t}, 4 \mathrm{H}$, $J=6 \mathrm{~Hz}$, aliphatic $\left.\mathrm{O}-\left(\mathrm{CH}_{2}\right)_{2}\right), 3.1\left(\mathrm{t}, 4 \mathrm{H}, J=6 \mathrm{~Hz}\right.$, aliphatic $\left.\mathrm{N}-\left(\mathrm{CH}_{2}\right)_{2}\right)$. MS (m/z): $277\left(\mathrm{C}_{14} \mathrm{H}_{14} \mathrm{ClN}_{3} \mathrm{O}, 9.66 \%, \mathrm{M}^{+}+2\right), 275\left(\mathrm{C}_{14} \mathrm{H}_{14} \mathrm{ClN}_{3} \mathrm{O}\right.$, $\left.29.59 \%, \mathrm{M}^{+}\right), 240\left(\mathrm{C}_{14} \mathrm{H}_{14} \mathrm{~N}_{3} \mathrm{O}, 23.2 \%\right), 189\left(\mathrm{C}_{10} \mathrm{H}_{6} \mathrm{ClN}_{2}, 100 \%\right)$. Anal. Calc. for: $\left(\mathrm{C}_{14} \mathrm{H}_{14} \mathrm{ClN}_{3} \mathrm{O}\right)$ (M.W.=275): C, 60.98; H, 5.12; N, 15.28\%; Found: C, 60.91; H, 4.98; N, 15.43\%.

\section{I-(2-Chloroquinolin-3-yl)-N-(4-methylpiperazin- I-yl) methanimine (I7)}

Light brown powder. Yield: $75 \%$. m.p.: $105{ }^{\circ} \mathrm{C} .1 \mathrm{H}$ NMR
(DMSO- $d_{6}$ ) $\delta$ ppm: $9.2(\mathrm{~s}, 1 \mathrm{H}$, quinoline-H4), $8.5(\mathrm{~s}, 1 \mathrm{H}, \mathrm{CH}=\mathrm{N}), 8.44$ (d, $1 \mathrm{H}, J=8 \mathrm{~Hz}$, quinoline-H5), $8.01(\mathrm{~d}, 1 \mathrm{H}, J=8 \mathrm{~Hz}$, quinoline-H8), $7.83(\mathrm{t}, 1 \mathrm{H}, J=9 \mathrm{~Hz}$, quinoline-H7), $7.67(\mathrm{t}, 1 \mathrm{H}, J=9 \mathrm{~Hz}$, quinoline-H6). $3.11\left(\mathrm{t}, 4 \mathrm{H}, J=6 \mathrm{~Hz}\right.$, aliphatic $\left.\mathrm{N}-\left(\mathrm{CH}_{2}\right)_{2}\right), 2.34(\mathrm{t}, 4 \mathrm{H}, J=6 \mathrm{~Hz}$, aliphatic $\left.\mathrm{N}-\left(\mathrm{CH}_{2}\right)_{2}\right), 1.89\left(\mathrm{~s}, 3 \mathrm{H}, \mathrm{CH}_{3}\right)$. MS $(\mathrm{m} / z): 290\left(\mathrm{C}_{15} \mathrm{H}_{17} \mathrm{ClN}_{4}, 11.66 \%\right.$, $\left.\mathrm{M}^{+}+2\right), 288\left(\mathrm{C}_{15} \mathrm{H}_{17} \mathrm{ClN}_{4}, 35.66 \%, \mathrm{M}^{+}\right), 253\left(\mathrm{C}_{15} \mathrm{H}_{17} \mathrm{~N}_{4}, 25.2 \%\right), 189$ $\left(\mathrm{C}_{10} \mathrm{H}_{6} \mathrm{~N}_{2} \mathrm{Cl}, 100 \%\right)$. Anal. Calc. for: $\left(\mathrm{C}_{15} \mathrm{H}_{17} \mathrm{ClN}_{4}\right)$ (M.W.=288): C, 62.39; H, 5.93; N, 19.40\%; Found: C, 62.39; H, 5.99; N, 19.23\%.

\section{General method for synthesis of compounds I 8-2 I}

General method: A mixture of chalcone (3) (3g, 10mmol), sodium hydroxide $(1.2 \mathrm{~g}, 30 \mathrm{mmol})$ and different dipoles namely, metformine hydrochloride, hydroxyl amine hydrochloride, thiourea, and guanidine hydrochloride was stirred in ethanol $(25 \mathrm{ml})$. The mixture was heated at reflux for $23 \mathrm{~h}$. After completion of the reaction, the solvent was concentrated under vaccum and poured into ice water $(50 \mathrm{ml})$. The obtained precipitate was filtered off, washed and recrystallized from ethanol to afford compounds $\mathbf{1 8 - 2 1}$.

\section{3-[4-(2-Chloroquinolin-3-yl)-6-(4-aminophenyl)} pyrimidin-2-yl]- I, I-dimethylguani- dine ( 8 )

Buff solid. Yield: $65 \%$; m.p. $131{ }^{\circ} \mathrm{C}$. IR $(\mathrm{KBr}) \mathrm{cm}^{-1}: 3350\left(\mathrm{NH}_{2}\right)$, $3290(\mathrm{NH}), 3050$ ( $\mathrm{CH}$ aromatic). 1H NMR (DMSO- $\left.d_{6}\right) \delta$ ppm: 9.30 (s, $1 \mathrm{H}, \mathrm{NH}, \mathrm{D}_{2} \mathrm{O}$ exchangeable $\left.\mathrm{H}\right), 8.53(\mathrm{~s}, 1 \mathrm{H}$, quinoline- $\mathrm{H} 4), 8.45$ (s, $1 \mathrm{H}$, pyrimidine- $\mathrm{H} 5), 8.23(\mathrm{~d}, 1 \mathrm{H}, J=9 \mathrm{~Hz}$, quinoline- $\mathrm{H} 5), 7.86(\mathrm{~d}$, $1 \mathrm{H}, J=9 \mathrm{~Hz}$, quinoline-H8), $7.5(\mathrm{t}, 1 \mathrm{H}, J=9 \mathrm{~Hz}$, quinoline-H7), 7.40 (t, $1 \mathrm{H}, J=9 \mathrm{~Hz}$, quinoline-H6), 7.30 (d, 2H, $J=9 \mathrm{~Hz}$, phenyl-H2, H6), $6.90\left(\mathrm{~d}, 2 \mathrm{H}, J=9 \mathrm{~Hz}\right.$, phenyl-H3, H5), $5.6\left(\mathrm{~s}, 2 \mathrm{H}, \mathrm{NH}_{2}\right.$ of C=NH, $\mathrm{D}_{2} \mathrm{O}-$ exchangeable proton), $2.80\left(\mathrm{~s}, 6 \mathrm{H}, 2 \mathrm{CH}_{3}\right)$. MS $(\mathrm{m} / \mathrm{z}): 419\left(\mathrm{C}_{22} \mathrm{H}_{20} \mathrm{ClN}_{7}\right.$, $\left.2.3 \%, \mathrm{M}^{+}+2\right), 417\left(\mathrm{C}_{22} \mathrm{H}_{20} \mathrm{ClN}_{7}, 7.6 \%, \mathrm{M}^{+}\right) 382\left(\mathrm{C}_{19} \mathrm{H}_{14} \mathrm{~N}_{7}, 4.15 \%\right), 215$ $\left(\mathrm{C}_{13} \mathrm{H}_{10} \mathrm{ClN}, 16 \%\right), 118\left(\mathrm{C}_{9} \mathrm{H}_{10}, 100 \%\right)$, Anal. Calc. for: $\left(\mathrm{C}_{22} \mathrm{H}_{19} \mathrm{ClN}_{7}\right)$ (M.W.=417): C, 63.23; H, 4.82; N, 23.46\%; Found: C, 63.65; H, 4.76 $\mathrm{N}, 23.93 \%$.

\section{5-(2-Chloroquinolin-3-yl)-3-(4-aminophenyl)-4,} 5-dihydroisoxazole (19)

Reddish solid. Yield: $65 \%$; m.p. $140^{\circ} \mathrm{C}$. IR $(\mathrm{KBr}) \mathrm{cm}^{-1}: 3050(\mathrm{CH}$ aromatic), $2950\left(\mathrm{CH}\right.$ aliphatic), $1590(\mathrm{C}=\mathrm{N}) .1 \mathrm{H}$ NMR $\left(\mathrm{DMSO}-d_{6}\right) \delta$ ppm: 8.87 (s, $1 \mathrm{H}$, quinoline-H4), $8.15(\mathrm{~d}, 1 \mathrm{H}, J=9 \mathrm{~Hz}$, quinoline-H8), 7.95 (t, $1 \mathrm{H} . J=9 \mathrm{~Hz}$, quinoline-H7), 7.84 (d, 2H, $J=9 \mathrm{~Hz}$, phenyl$\mathrm{H} 2, \mathrm{H} 6), 7.75$ (d, 1H, $J=9 \mathrm{~Hz}$, quinoline-H5), 7.40 (t, $1 \mathrm{H}, J=9 \mathrm{~Hz}$, quinoline- H6), $6.66(\mathrm{~d}, 2 \mathrm{H}, J=9 \mathrm{~Hz}$, phenyl-H3,H5), $6.20(\mathrm{t}, 1 \mathrm{H}$, $J=14 \mathrm{~Hz}$, isoxazole-H5 ), 4 (dd, $1 \mathrm{H}, J=11,5 \mathrm{~Hz}$, isoxazole- $\mathrm{H} 4$ axial), $4.1\left(\mathrm{~s}, 2 \mathrm{H}, \mathrm{NH}_{2}, \mathrm{D}_{2} \mathrm{O}\right.$-exchaneable), $2.9(\mathrm{dd}, 1 \mathrm{H}, J=17,4.8 \mathrm{~Hz}$, isoxazole-H4 equatorial). $\mathbf{M S}(\mathrm{m} / \mathrm{z}): 325\left(\mathrm{C}_{18} \mathrm{H}_{14} \mathrm{ClN}_{3} \mathrm{O}, 15 \%, \mathrm{M}^{+}+2\right)$, $323\left(\mathrm{C}_{18} \mathrm{H}_{14} \mathrm{ClN}_{3} \mathrm{O}, 42 \%, \mathrm{M}^{+}\right), 231\left(\mathrm{C}_{12} \mathrm{H}_{8} \mathrm{ClN}_{2} \mathrm{O}, 19 \%\right), 200\left(\mathrm{C}_{1} 1 \mathrm{H}\right.$ $\left.{ }_{8} \mathrm{~N}_{2} \mathrm{O}_{2}, 33 \%\right), 118\left(\mathrm{C}_{9} \mathrm{H}_{10}, 100 \%\right)$. Anal. Calc. for: $\left(\mathrm{C}_{18} \mathrm{H}_{14} \mathrm{ClN}_{3} \mathrm{O}\right)$ (M.W.=323): C, 66.77; H, 4.36; N, 12.80\%; Found: C, 66.63; H, 4.27; $\mathrm{N}, 12.60 \%$

\section{4-(4-aminophenyl)-6-(2-chloroquinolin-3-yl)} pyrimidine-2(I $\mathrm{H})$-thione (20)

Dark yellow solid. Yield: $40 \%$; m.p. $150{ }^{\circ} \mathrm{C}$. IR $(\mathrm{KBr}) \mathrm{cm}^{-1}$ : $3290(\mathrm{NH}), 3350\left(\mathrm{NH}_{2}\right) 3050$ (CH aromatic). 1H NMR (DMSO- $\left.d_{6}\right)$ $\delta \mathrm{ppm}: 12.30\left(\mathrm{~s}, 1 \mathrm{H}, \mathrm{NH}, \mathrm{D}_{2} \mathrm{O}\right.$-exchangeable proton), $8.50(\mathrm{~s}, 1 \mathrm{H}$, quinoline-H4), $8.30(\mathrm{~d}, 1 \mathrm{H}, J=15 \mathrm{~Hz}$, quinoline-H5), $8.10(\mathrm{~d}, 1 \mathrm{H}$, $J=9$ quinoline-H8), $7.98(\mathrm{t}, 1 \mathrm{H}, J=8 \mathrm{~Hz}$, quinoline- $\mathrm{H} 7), 7.88(\mathrm{~d}, 2 \mathrm{H}$, $J=7 \mathrm{~Hz}$, phenyl-H2,H6), 7.4 (t, $1 \mathrm{H}, J=9 \mathrm{~Hz}$, quinoline-H6), 7.1 (d, $2 \mathrm{H}, J=9 \mathrm{~Hz}$, phenyl-H3,H5), 6.5 (s, 1H, pyrimidine-thion), 4.1 (s, $2 \mathrm{H}, \mathrm{NH}_{2}, \mathrm{D}_{2} \mathrm{O}$-exchangeable proton). $\mathrm{MS}(\mathrm{m} / \mathrm{z}): 366\left(\mathrm{C}_{10} \mathrm{H}_{13} \mathrm{ClN}_{4} \mathrm{~S}\right.$, 
0.15\%, $\left.\mathrm{M}^{+}+2\right), 364\left(\mathrm{C}_{19} \mathrm{H}_{13} \mathrm{ClN}_{4} \mathrm{~S}, 0.5 \%, \mathrm{M}^{+}\right), 329\left(\mathrm{C}_{19} \mathrm{H}_{13} \mathrm{~N}_{4} \mathrm{~S}, 4 \%\right)$, $77\left(\mathrm{C}_{6} \mathrm{H}_{5}, 100 \%\right)$. Anal. Calc. for: $\left(\mathrm{C}_{10} \mathrm{H}_{13} \mathrm{ClN}_{4} \mathrm{~S}\right)(\mathrm{M} . \mathrm{W} .=364)$ : C, 62.55; H, 3.59; N, 15.36\%; Found: C, 62.96; H, 3.31; N, 15.78\%.

\section{4-(2-Chloroquinolin-3-yl)-6-(4-aminophenyl) pyrimidin-2-amine (2I)}

Yellow solid. Yield: $60 \%$; m.p. $195^{\circ} \mathrm{C}$. IR $(\mathrm{KBr}) \mathrm{cm}^{-1}: 3300$ $\left(\mathrm{NH}_{2}\right), 3050$ (CH aromatic-H's). 1H NMR (DMSO- $\left.d_{6}\right) \delta \mathrm{ppm:} 8.73$ (s, $1 \mathrm{H}$, quinoline- $\mathrm{H} 4), 8.17(\mathrm{~d}, 1 \mathrm{H}, J=9 \mathrm{~Hz}$, quinoline-H5), 8.1 (s, $1 \mathrm{H}$, pyrimidine- $\mathrm{H} 5), 7.9(\mathrm{~d}, 1 \mathrm{H}, J=9 \mathrm{~Hz}$, quinoline- $\mathrm{H} 8), 7.59(\mathrm{t}, 1 \mathrm{H}$, $J=9 \mathrm{~Hz}$, quinoline- $\mathrm{H} 7), 7.5$ (t, 1H, $J=9 \mathrm{~Hz}$, quinoline-H6), $7.4(\mathrm{~d}, 2 \mathrm{H}$, $J=9 \mathrm{~Hz}$, phenyl-H2, H6), 7.1 (d, 2H, $J=9 \mathrm{~Hz}$, phenyl-H3, H5), 6.5 (s, $2 \mathrm{H}, \mathrm{NH}_{2}$ of pyrimidine, $\mathrm{D}_{2} \mathrm{O}$-exchangeable), 5.5 (s, $2 \mathrm{H}, \mathrm{NH}_{2}$ of phenyl, $\mathrm{D}_{2} \mathrm{O}$-exchangeable). MS $(\mathrm{m} / \mathrm{z}): 349\left(\mathrm{C}_{19} \mathrm{H}_{14} \mathrm{ClN}_{5}, 1.3 \%, \mathrm{M}^{+}+2\right), 347$ $\left(\mathrm{C}_{19} \mathrm{H}_{14} \mathrm{ClN}_{5}, 4.01 \%, \mathrm{M}^{+}\right) 312\left(\mathrm{C}_{19} \mathrm{H}_{14} \mathrm{~N}_{5}, 9.15 \%, \mathrm{M}^{+}\right), 215\left(\mathrm{C}_{13} \mathrm{H}_{10} \mathrm{ClN}\right.$, $16 \%), 118\left(\mathrm{C}_{9} \mathrm{H}_{10}, 100 \%\right)$, Anal. Calc. for: $\left(\mathrm{C}_{19} \mathrm{H}_{14} \mathrm{ClN}_{5}\right)(\mathrm{M} . \mathrm{W} .=347)$ : C, 65.61; H, 4.06; N, 20.14\%; Found: C, 65.95; H, 3.96; N, 20.03\%.

\section{6-(2-Chloroquinolin-3-yl)-4-(4-aminophenyl) pyrimidin-2( $\mathrm{IH}$ )-one (22)}

A mixture of chalcone (3) $(3 \mathrm{~g}, 10 \mathrm{mmol})$ and urea $(1.8 \mathrm{~g}, 30 \mathrm{mmol})$ was stirred in ethanol $(20 \mathrm{ml})$, and then hydrochloric acid $(3 \mathrm{ml})$ was added. The mixture was heated at reflux for $12 \mathrm{~h}$. After completion the reaction, the solvent was concentrated under reduced pressure and poured into ice water $(50 \mathrm{ml})$. The obtained precipitate was filtered off, washed and recrystallized from ethanol to yield the titled compound as brown solid.Yield: $60 \%$; m.p. $180^{\circ} \mathrm{C}$. IR $(\mathrm{KBr}) \mathrm{cm}^{-1}: 3300\left(\mathrm{NH}_{2}\right)$ $3290(\mathrm{NH}), 3050$ (CH aromatic). 1H NMR (DMSO- $\left.d_{6}\right) \delta \mathrm{ppm:} 11.99$ (s, $1 \mathrm{H}, \mathrm{NH}, \mathrm{D}_{2} \mathrm{O}$-exchangeable), $8.53(\mathrm{~s}, 1 \mathrm{H}$, quinoline-H4), 8.33 (s, $\mathrm{H}$, pyrimidinone- $\mathrm{H} 5), 8.23$ (d, $1 \mathrm{H}, J=15 \mathrm{~Hz}$, quinoline- $\mathrm{H} 5), 7.86(\mathrm{~d}$, $1 \mathrm{H}, J=9 \mathrm{~Hz}$, quinoline-H8), $7.73(\mathrm{t}, 1 \mathrm{H}, J=9 \mathrm{~Hz}$, quinoline- $\mathrm{H} 7), 7.5$ (d, $2 \mathrm{H}, J=7 \mathrm{~Hz}$, phenyl-H2, H6), 7.4 (t, $1 \mathrm{H}, J=9 \mathrm{~Hz}$, quinoline-H6), 6.65 (d, $2 \mathrm{H}, J=9 \mathrm{~Hz}$, phenyl-H3, H5), 6.14 (s, 2H, $\mathrm{NH}_{2}, \mathrm{D}_{2} \mathrm{O}$-exchangeable). MS $(m / z): 350\left(\mathrm{C}_{19} \mathrm{H}_{13} \mathrm{ClN}_{4} \mathrm{O}, 1.6 \%, \mathrm{M}^{+}+2\right), 348\left(\mathrm{C}_{19} \mathrm{H}_{13} \mathrm{ClN}_{4} \mathrm{O}\right.$, $\left.4 \%, \mathrm{M}^{+}\right), 313\left(\mathrm{C}_{19} \mathrm{H}_{13} \mathrm{~N}_{4} \mathrm{O}, 4 \%\right), 77\left(\mathrm{C}_{6} \mathrm{H}_{5}, 100 \%\right)$. Anal. Calc. for: $\left(\mathrm{C}_{19} \mathrm{H}_{13} \mathrm{ClN}_{4} \mathrm{O}\right)(\mathrm{M} . \mathrm{W} .=348)$ : C, 65.43; H, 3.76; N, 16.06\%; Found: $\mathrm{C}$, $65.96 ; \mathrm{H}, 3.81 ; \mathrm{N}, 16.08 \%$.

\section{2-Chloro-3-[3-(4-aminophenyl)-4,5-dihydro- I H -pyrazol-5-yl] quinoline (23)}

A mixture of chalcone (3) (3g, 10mmol) and hydrazine hydrate (1 $\mathrm{ml}, 20 \mathrm{mmol})$ was stirred in ethanol $(20 \mathrm{ml})$ and heated at reflux for $22 \mathrm{~h}$. After completion of the reaction, the mixture was concentrated by evaporating out the solvent under reduced pressure, and then poured onto ice water. The obtained precipitate was filtered off, washed by water and recrystallized from ethanol to afford compound IX as white needles.Yield: $60 \%$; m.p. $105{ }^{\circ} \mathrm{C}$. IR (KBr) $\mathrm{cm}^{-1}: 3290$ $(\mathrm{NH}), 3300\left(\mathrm{NH}_{2}\right) 3050(\mathrm{CH}$ aromatic), $2950(\mathrm{CH}$ aliphatic). 1H NMR (DMSO- $\left.d_{6}\right) \delta$ ppm: 8.53 (s, 1H, NH, $\mathrm{D}_{2} \mathrm{O}$-exchaneable), 8.19 (s, $1 \mathrm{H}$, quinoline- $\mathrm{H} 4), 8.07(\mathrm{~d}, 1 \mathrm{H}, J=9 \mathrm{~Hz}$, quinoline- $\mathrm{H} 8), 7.97(\mathrm{t}, 1 \mathrm{H}$ $. J=9 \mathrm{~Hz}$, quinoline- $\mathrm{H} 7), 7.85\left(\mathrm{~d}, 2 \mathrm{H}, J=9 \mathrm{~Hz}\right.$, phenyl- $\left.\mathrm{H}_{2}, \mathrm{H} 6\right), 7.76(\mathrm{~d}$, $1 \mathrm{H}, J=9 \mathrm{~Hz}$, quinoline-H5), $7.30(\mathrm{t}, 1 \mathrm{H}, J=9 \mathrm{~Hz}$, quinoline- $\mathrm{H} 6), 6.55$ (d, $2 \mathrm{H}, J=9 \mathrm{~Hz}$, phenyl- $\left.\mathrm{H}_{3}, \mathrm{H} 5\right), 5.10(\mathrm{t}, 1 \mathrm{H}, J=9.2 \mathrm{~Hz}$, pyrazole-H5), 4.10 (s, $2 \mathrm{H}, \mathrm{NH}_{2} \mathrm{D}_{2} \mathrm{O}$-exchaneable), $3.60(\mathrm{dd}, 1 \mathrm{H}, J=16,9.2 \mathrm{~Hz}$, pyrazole$\mathrm{H} 4$ axial), 2.90 (dd, $1 \mathrm{H}, J=16.4,9.2 \mathrm{~Hz}$, pyrazole-H4 equatorial). MS $(\mathrm{m} / \mathrm{z}): 324\left(\mathrm{C}_{18} \mathrm{H}_{15} \mathrm{ClN}_{4}, 15 \%, \mathrm{M}^{+}+2\right), 322\left(\mathrm{C}_{18} \mathrm{H}_{15} \mathrm{ClN}_{4}, 47.9 \%, \mathrm{M}^{+}\right)$, $287\left(\mathrm{C}_{18} \mathrm{H}_{15} \mathrm{~N}_{4}, 10 \%\right), 155\left(\mathrm{C}_{10} \mathrm{H}_{7} \mathrm{~N}_{2}, 27 \%\right), 135\left(\mathrm{C}_{10} \mathrm{H}_{6} \mathrm{~N}, 100 \%\right)$. Anal. Calc. for: $\left(\mathrm{C}_{18} \mathrm{H}_{15} \mathrm{ClN}_{4}\right)(\mathrm{M} . \mathrm{W} .=322)$ : $\mathrm{C}, 66.98 ; \mathrm{H}, 4.68 ; \mathrm{N}, 17.36 \%$; Found: C, 66.91; H, 4.39; N, 17.53\%.

\section{2-Amino-6-(4-aminophenyl)-4-(2-chloroquinoline-3- yl)nicotinonitrile (24)}

A mixture of chalcone (3) $(3 \mathrm{~g}, 10 \mathrm{mmol})$ and malononitrile $(1.32$ $\mathrm{g}, 20 \mathrm{mmol})$, was stirred in ethanol $(20 \mathrm{ml})$, and then anhydrous ammonium acetate $(2.31 \mathrm{~g}, 30 \mathrm{mmole})$, was added. The reaction mixture was heated at reflux for $22 \mathrm{~h}$. After completion the reaction, the solvent was concentrated by vaporization under reduced pressure, and poured onto ice water $(50 \mathrm{ml})$, the obtained precipitate was filtered off, washed and recrystallized from ethanol to afford compound $\mathbf{2 4}$ as brownish solid. Yield: $60 \%$;m.p. $160{ }^{\circ} \mathrm{C} .1 \mathrm{H} \mathrm{NMR}$ (DMSO- $\left.d_{6}\right) \delta$ ppm: 8.72 (s, $1 \mathrm{H}$, quinoline- $\mathrm{H} 4), 8.31(\mathrm{~d}, 1 \mathrm{H}, J=9 \mathrm{~Hz}$, quinoline-H5), 8.02 (d, 2H, $J=9 \mathrm{~Hz}$, phenyl-H2, H6), 7.70 (d, 1H, $J=9 \mathrm{~Hz}$, quinoline-H8), 7.50 (s, $1 \mathrm{H}, J=9 \mathrm{~Hz}$, pyridine-H5) 7.31 (t, $1 \mathrm{H}, J=9 \mathrm{~Hz}$, quinoline- $\mathrm{H} 7$ ), 7.20 (t, $1 \mathrm{H}, J=9 \mathrm{~Hz}$, quinoline-H6), $7.12\left(\mathrm{~s}, 2 \mathrm{H}\right.$, pyridine- $\mathrm{NH}_{2}, \mathrm{D}_{2} \mathrm{O}$ exchangeable), 6.99 (d, 2H, $J=9 \mathrm{~Hz}$, phenyl-H3, H5), 5.52 (s, $2 \mathrm{H}$, phenyl- $\mathrm{NH}_{2}, \mathrm{D}_{2} \mathrm{O}$ exchangeable). MS $(\mathrm{m} / \mathrm{z}): 373\left(\mathrm{C}_{2} 1 \mathrm{H}_{14} \mathrm{ClN}_{5}, 3.6 \%\right.$, $\left.\mathrm{M}^{+}+2\right), 371\left(\mathrm{C}_{1} 1 \mathrm{H}{ }_{14} \mathrm{ClN}_{5}, 10.4 \%, \mathrm{M}^{+}\right), 338\left(\mathrm{C}_{2} 1 \mathrm{H}_{14} \mathrm{~N}_{5}, 4 \%\right), 299$ $\left(\mathrm{C}_{20} \mathrm{H}_{17} \mathrm{~N}_{3}, 100 \%\right), 286\left(\mathrm{C}_{20} \mathrm{H}_{18} \mathrm{~N}_{2}, 2.85 \%\right)$. Anal. Calc. for: $\left(\mathrm{C}_{2} 1 \mathrm{H}\right.$ ${ }_{14} \mathrm{ClN}_{5}$ ) (M.W.=371): C, 67.83; H, 3.80; N, 18.84\%; Found: C, 67.49; H, 3.93; N, $18.93 \%$.

\section{Antimicrobial screening}

\section{Preparation of bacterial and fungal suspensions and solution of the tested compounds}

The newly synthesized compounds were dissolved in DMSO at $1 \mathrm{mg} / \mathrm{ml}$ concentration and tested against Aspergillus fumigatus, Geotricum candidum, Syncephalastrum racemosum, Candida albicans, Streptococcus pneumoniae, Bacillus subtilis, Pseudomonas aeruginosa and Escherichia coli obtained from the Regional Center for Mycology and Biotechnology, Faculty of Science, Al-Azhar University. Ampicillin and gentamicin were used as antibacterial standards and amphotericin B was used as antifungal standard using agar diffusion technique ${ }^{24}$ and minimum inhibitory concentration (MIC). ${ }^{25}$ The standards were dissolved in DMSO at $1 \mathrm{mg} / \mathrm{ml}$ concentration. The bacterial and the fungal suspension were prepared by inoculating fresh stock cultures into separate broth tubes, each containing $7 \mathrm{ml}$ of nutrient broth. The inoculated tubes were incubated at $37^{\circ} \mathrm{C}$ for 24 and $48 \mathrm{~h}$ respectively.

\section{Agar diffusion test for detection of antibacterial and antifungal activity:}

Nutrient agar for bacterial growth and Potato-dextrose-agar for fungal growth were dissolved and distributed in $25 \mathrm{ml}$ quantities in $100 \mathrm{ml}$ conical flasks and was sterilized in an autoclave at $121^{\circ} \mathrm{C}$ for 20minutes. The media were poured in Petri dishes and allowed to set for 30 minutes at room temperature. Cultures of each organism were spread with a dry sterile swab on the surface of the previously prepared plates. Cups of $6 \mathrm{~mm}$ at equal distances were made in each plate. In each plate one cup was used for control (DMSO) and other for standard (Ciprofloxacine, Ampicillin, Gentamicin, and Amphotericin $B$ ) where the other cups were used for the tested compounds. The plates were incubated at $37^{\circ} \mathrm{C}$ for $24 \mathrm{~h}$ in bacterial growth and 48 in fungal growth then the plates were examined for inhibition zones.

\section{Determination of minimal inhibitory concentration (MIC):}

The inoculums were prepared by taking a loopful of stoke culture to about $100 \mathrm{ml}$ of nutrient broth, in $250 \mathrm{ml}$ clean and sterilized 
conical flasks. The flasks were incubated at $27^{\circ} \mathrm{C}$ for $24 \mathrm{~h}$ before use. The plates were kept undisturbed for at least two hours at room temperature to allow diffusion of the solution properly, into potatodextrose-agar medium. Then the plates were incubated at $25^{\circ} \mathrm{C}$ for $48 \mathrm{hr}$. The highest dilution showing at least $99 \%$ inhibition zone is taken as MIC. The result of this is much affected by the size of the inoculums. The experiments were performed in triplicate in order to minimize the errors.

\section{Results and discussion}

\section{Molecular modeling}

The obtained results indicated that all studied ligands have similar position and orientation inside the putative binding site of type IIA topoisomerase protein. The selected compounds (14, 22 and 10) showed good binding energies ranging from -15.60 to $-33.11 \mathrm{kcal} / \mathrm{mol}$ (Table 1). The proposed binding mode of the ligand (ciprofloxacin) binding free energy was $-33.32 \mathrm{kcal} / \mathrm{mol}$ with RMSD value of 2.8 . It showed the important interactions with the residues at the active site of type IIA topoisomerase protein (Figure 2A). The piprazine group formed a hydrogen bond of $2.02 \mathrm{~A}^{\circ}$ with Asp 1083. The proposed binding mode of compound 14 (affinity value of $-26.60 \mathrm{kcal} / \mathrm{mol}$ and $2 \mathrm{H}$-bonds) is virtually the same as that of ciprofloxacine (Figure 2B). The hydrazine group formed a hydrogen bond with a distance of $2.09 \mathrm{~A}^{\circ}$ with Asp 1083. The nitrile group formed a further hydrogen bond with a distance of $2.30 \mathrm{~A}^{\circ}$ with Ser 1084 .

The proposed binding mode of compound 22 (affinity value of
- 27.28kcal $/ \mathrm{mol}$ and one H-bond) is virtually the same as that of ciprofloxacine (Figure 2C). The pyrimidione group formed a hydrogen bond with a distance of $2.06 \mathrm{~A}^{\circ}$ with Asp 1083. The proposed binding mode of compound 10 (affinity value of $-33.11 \mathrm{kcal} / \mathrm{mol}$ and one $\mathrm{H}$-bonds) is virtually the same as that of ciprofloxacine (Figure 2D). The hydrazino group formed a hydrogen bond with a distance of $2.10 \mathrm{~A}^{\circ}$ with Asp 1083. These interactions of compounds 14, 22 and 10 with type IIA topoisomerase protein explain the high binding free enrgies and the biological activities.

\section{Chemistry}

The sequence of reactions used in the synthesis of the target compounds is illustrated in Schemes 1-3. Vilsmeier formulation of $\mathrm{N}$-phenylacetamide(1) afforded 2-chloroquinoline-3-carbaldehyde (2) followed by condensation with 4-amino acetophenone to afford 1-(4-aminophenyl)-3-(2-chloroquinolin-3-yl) prop-2-en-1one (chalcone) (3). Treatment of 2 with hydroxyl amine produced 2-chloroquinoline-3-carbonitrile (4) then reaction of 4 with thiourea yielded 2-mercaptoquinoline-3-carbonitrile (5), and subsequent treatment with both alkyl halides and substituted chloroacetanilide to to afford $6_{\mathrm{a}-\mathrm{d}}$ and 7 a-d respectively (Scheme 1). Compound 2 was condensed with different primary amine or substituted hydrazide derivatives to afford the title compounds 8-17 (Scheme 2). Compound 3 underwent a 1,3-dipolar cyclo-addition reaction with seven different dipoles namely hydrazine hydrate, hydroxylamine hydrochloride, thiourea, guanidine hydrochloride, urea, metformine hydrochloride, and malononitrile, to produce the compounds 18-24 respectively (Scheme 3).

Table I The docking binding free energies of compounds..$^{2-24}$

\begin{tabular}{|c|c|c|c|}
\hline Comp. No. & Binding free energy (kcal/mol) & Comp. No & Binding free energy ( $\mathrm{kcal} / \mathrm{mol})$ \\
\hline 2 & -16.3 & 12 & -15.6 \\
\hline 3 & -18.1 & 13 & -17.8 \\
\hline $6 a$ & -23.45 & 14 & -26.60 \\
\hline $6 b$ & -18.85 & 15 & -17.98 \\
\hline $6 c$ & -17.44 & 16 & -18.33 \\
\hline $6 d$ & -24.22 & 17 & -19.34 \\
\hline $7 a$ & -22.5 & 18 & -22.8 \\
\hline $7 b$ & -16.23 & 19 & -22.11 \\
\hline $7 c$ & -22.7 & 20 & -19.45 \\
\hline $7 d$ & -22.1 & 21 & -20.56 \\
\hline 8 & -24.5 & 22 & -27.28 \\
\hline 9 & -20.9 & 23 & -21.1 \\
\hline 10 & -33.11 & 24 & -24.01 \\
\hline II & -25.33 & Ciprofloxacine & -33.32 \\
\hline
\end{tabular}




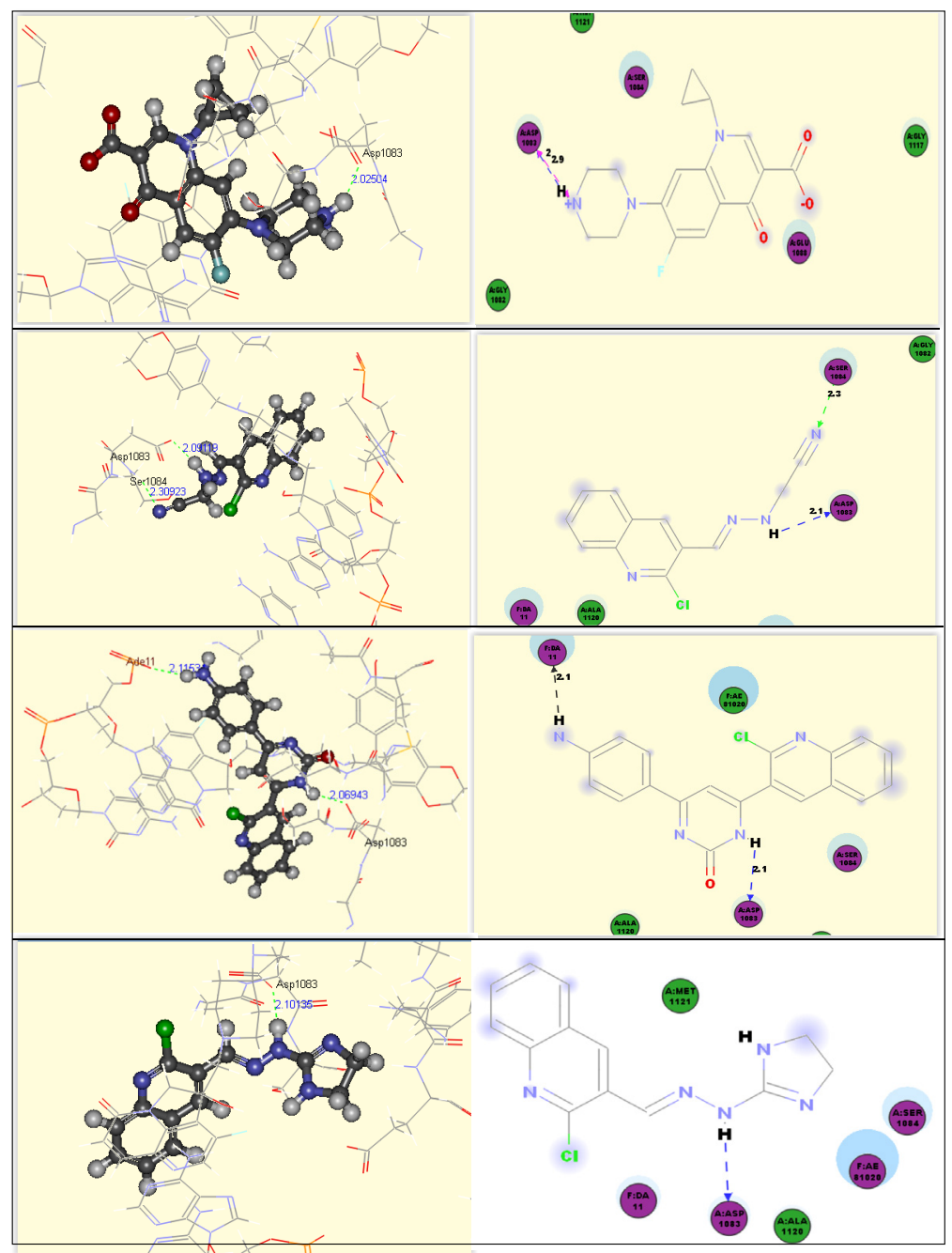

Figure 2: A) Binding interaction of Ciprofloxacin. B) Binding interaction of compound 14. C) Binding interaction of compound 22. D) Binding interaction of compound 10.

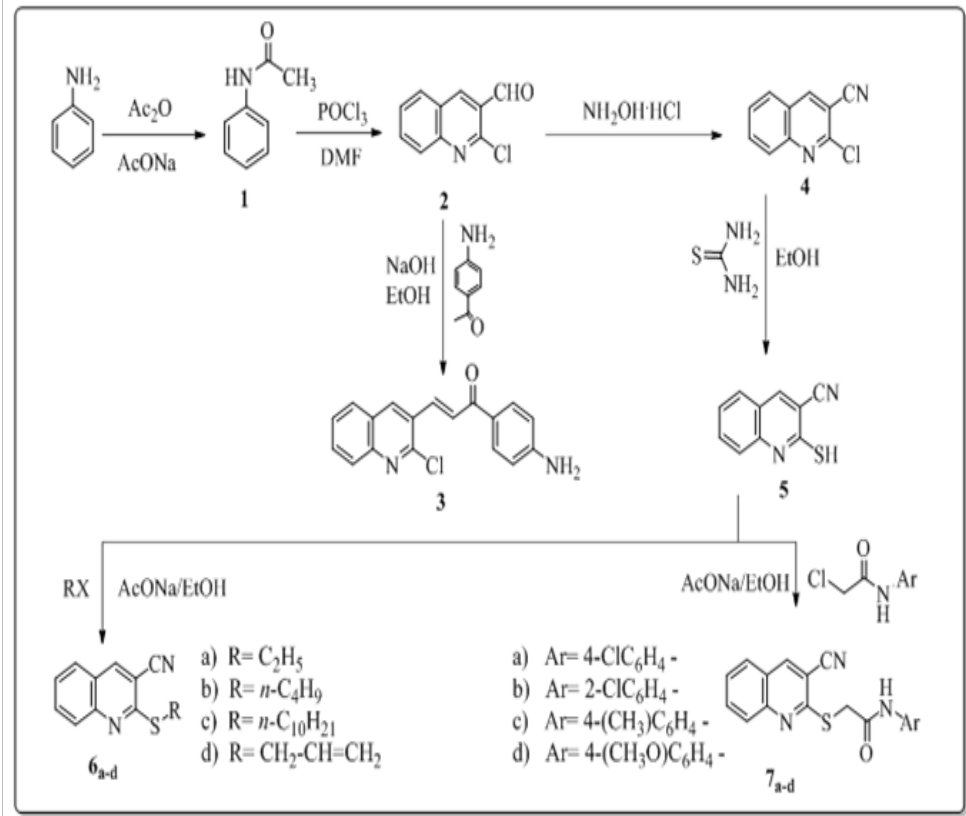

Scheme I General procedure for preparation of target compounds $6_{\mathrm{a}-\mathrm{d}}, 7_{\mathrm{a}-\mathrm{d}}$ 


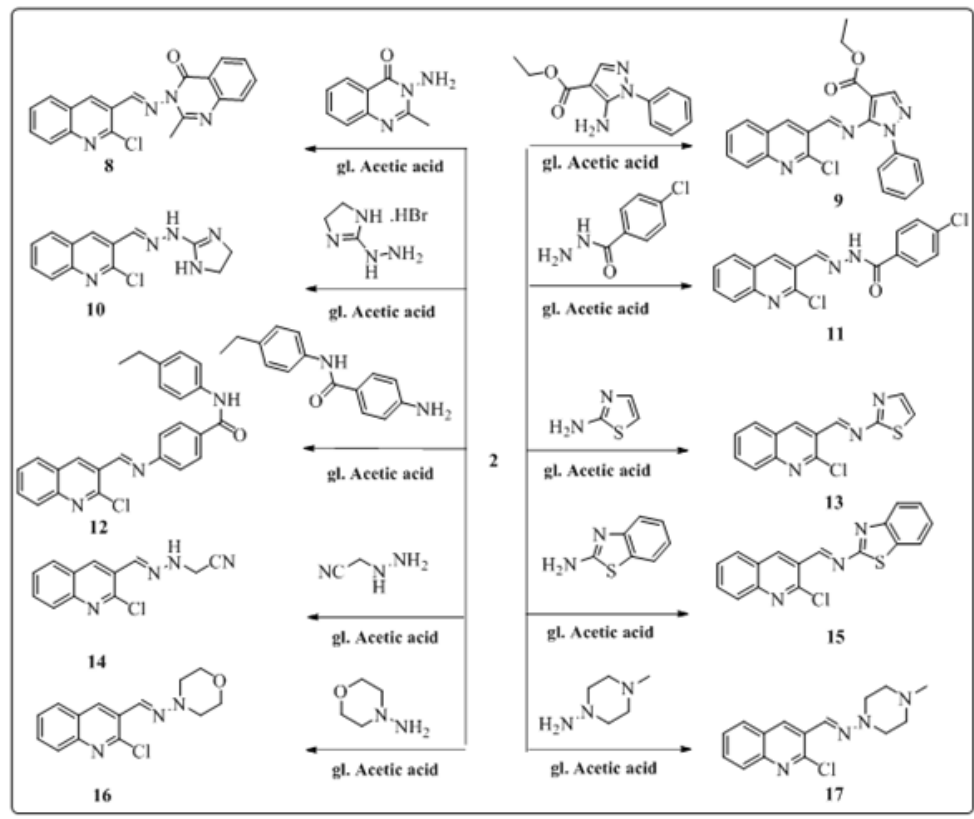

Scheme 2 General procedure for preparation of target compounds 8-17

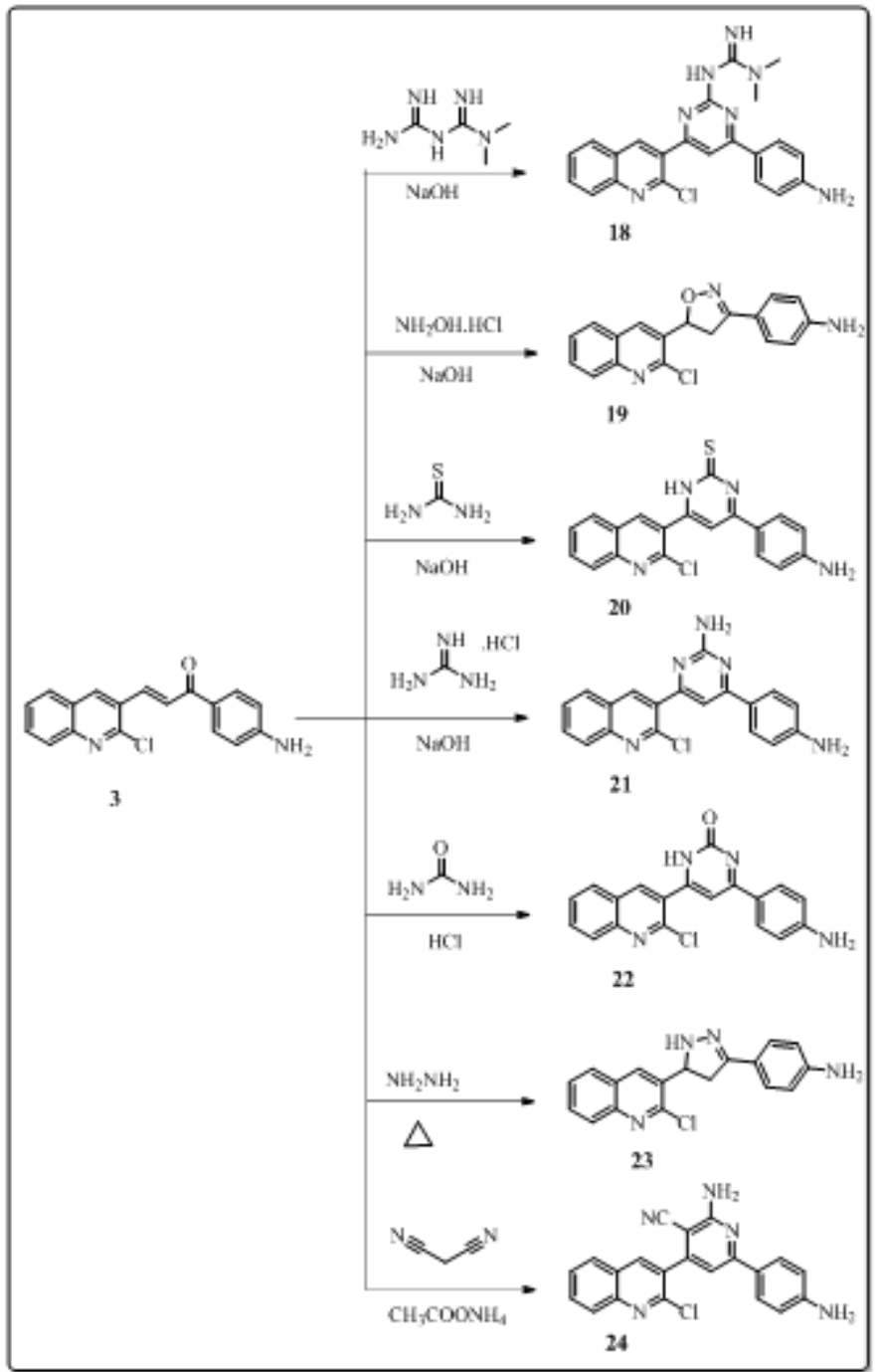

Scheme 3 General procedure for preparation of target compounds I8-24.

Citation: El-Gamal KMA, Sherbiny FF, El-Morsi AM, et al. Design, synthesis and antimicrobial evaluation of some novel quinoline derivatives. Pharm Pharmacol Int J. 2015;2(5):I65-177. DOI: 10.15406/ppij.2015.02.00036 


\section{Antimicrobial screening}

Antibacterial and antifungal activities of all newly synthesized compounds were tested by measuring the inhibitory effect of such compounds against some Gram-positive, Gram-negative bacteria and some fungi using agar diffusion technique and minimum inhibitory concentration (MIC). The newly synthesized compounds were evaluated for their in vitro antibacterial activity against Gram-positive namely Staphylococcus aureus (SA) and Bacillus subtilis (BS) and Gram-negative Pseudomonas aeuroginosa (PA) and Escherichia coli (EC). They were also evaluated for their in vitro antifungal activity against Aspergillus fumigatus (AF), Geotricum candidum(GC), Syncephalasteru mracemosum (SR), Candidaalbicans (CA). Ampicillin (AMP) was the standard used for the evaluation of antibacterial activity against gram positive bacteria and Gentamicin (Gent) was used as a standard in assessing the activity of the tested compounds against gram negative bacteria, and Ciprofloxacin $(\mathrm{Cf})$ was used as broad spectrum antibacterial positive control, while Amphotericin B (Amp-B) was taken as reference for the antifungal effect. The inhibitory effects of the synthetic compounds against these organisms are given in (Table 2) (Table 3) and (Figure 3) (Figure 4).

Table 2 Antifungal activities and antibacterial activities against Gram-positive and gram- negative organisms of compounds ${ }^{3-24}$

\begin{tabular}{|c|c|c|c|c|c|c|c|c|}
\hline \multirow[b]{2}{*}{ Comp. } & \multicolumn{2}{|c|}{ Gram Positive Bacteria } & \multicolumn{2}{|c|}{ Gram Negative Bacteria } & \multicolumn{4}{|l|}{ Fungi } \\
\hline & $S_{p}$ & B s & E c & $\mathrm{Pa}$ & Af & $S m$ & G $n$ & $\mathrm{Ca}$ \\
\hline 2 & $14.3 \pm 0.63$ & $16.2 \pm 0.24$ & $12.1 \pm 0.72$ & NA & $13.2 \pm 0.58$ & $13.9 \pm 0.24$ & $14.4 \pm 0.72$ & NA \\
\hline 3 & $18.2 \pm 0.19$ & $19.8 \pm 0.47$ & $18.2 \pm 0.58$ & NA & $17.7 \pm 0.38$ & $16.9 \pm 0.23$ & $19.8 \pm 0.34$ & NA \\
\hline 6 & $20.2 \pm 0.55$ & $21.9 \pm 0.52$ & $20.3 \pm 0.58$ & NA & $17.2 \pm 0.58$ & $19.3 \pm 0.19$ & $21.9 \pm 0.58$ & NA \\
\hline $6 b_{b}$ & $19.3 \pm 0.37$ & $21.3 \pm 0.72$ & $19.8 \pm 0.63$ & NA & $16.3 \pm 0.58$ & $18.4 \pm 0.19$ & $21.4 \pm 0.58$ & NA \\
\hline $6_{c}$ & $17.4 \pm 0.37$ & $19.3 \pm 0.63$ & $16.9 \pm 0.63$ & NA & $15.4 \pm 0.58$ & $17.3 \pm 0.63$ & $22.2 \pm 0.78$ & NA \\
\hline $6_{d}$ & $21.2 \pm 0.63$ & $23.2 \pm 0.58$ & $21.1 \pm 0.58$ & NA & $18.6 \pm 0.63$ & $21.2 \pm 0.72$ & $22.4 \pm 0.58$ & NA \\
\hline $7 a$ & $20.3 \pm 0.72$ & $21.2 \pm 0.58$ & $22.6 \pm 0.58$ & NA & $19.8 \pm 0.58$ & $18.7 \pm 0.58$ & $17.6 \pm 0.63$ & NA \\
\hline $7_{b}$ & $15.9 \pm 0.44$ & $16.3 \pm 0.58$ & $13.9 \pm 0.63$ & NA & $15.3 \pm 0.44$ & $18.4 \pm 0.58$ & $19.1 \pm 0.37$ & NA \\
\hline $7_{c}$ & $20.9 \pm 0.37$ & $21.5 \pm 0.28$ & $20.6 \pm 0.44$ & NA & $15.7 \pm 0.19$ & $14.8 \pm 0.19$ & $13.9 \pm 0.37$ & NA \\
\hline $7_{d}$ & $20.3 \pm 0.43$ & $21.4 \pm 0.53$ & $16.3 \pm 0.25$ & NA & $18.6 \pm 0.58$ & $17.3 \pm 0.25$ & $16.3 \pm 0.38$ & NA \\
\hline 8 & $22.1 \pm 0.44$ & $22.8 \pm 0.25$ & $20.5 \pm 0.44$ & NA & $20.6 \pm 0.44$ & $22.1 \pm 0.58$ & $22.9 \pm 0.37$ & NA \\
\hline 9 & $17.4 \pm 0.63$ & $18.6 \pm 0.58$ & $15.3 \pm 0.58$ & NA & $16.3 \pm 0.58$ & $17.4 \pm 0.63$ & $17.6 \pm 0.63$ & NA \\
\hline 10 & $25.3 \pm 0.72$ & $27.7 \pm 0.63$ & $22.2 \pm 0.72$ & NA & $22.3 \pm 0.58$ & $22.8 \pm 0.44$ & $24.1 \pm 0.53$ & NA \\
\hline II & $22.4 \pm 0.72$ & $25.2 \pm 0.72$ & $21.6 \pm 0.72$ & NA & $20.3 \pm 0.72$ & $21.4 \pm 0.72$ & $23.6 \pm 0.72$ & NA \\
\hline 12 & II. $4 \pm 0.44$ & $14.2 \pm 0.67$ & $10.4 \pm 0.46$ & NA & $20.3 \pm 0.72$ & $21.6 \pm 0.72$ & $24.6 \pm 0.72$ & NA \\
\hline 13 & $17.4 \pm 0.25$ & $16.2 \pm 0.63$ & $15.9 \pm 0.44$ & NA & $12.3 \pm 0.72$ & $14.3 \pm 0.72$ & $17.1 \pm 0.72$ & NA \\
\hline 14 & $25.4 \pm 0.27$ & $31.6 \pm 0.58$ & $23.3 \pm 0.25$ & NA & $24.3 \pm 0.72$ & $26.2 \pm 0.72$ & $28.3 \pm 0.72$ & NA \\
\hline 15 & $17.6 \pm 0.18$ & $17.8 \pm 0.19$ & $20.8 \pm 0.19$ & NA & II. $3 \pm 0.72$ & $14.3 \pm 0.72$ & $15.9 \pm 0.72$ & NA \\
\hline
\end{tabular}


Table Continued.

\begin{tabular}{|c|c|c|c|c|c|c|c|c|}
\hline \multirow[b]{2}{*}{ Comp. } & \multicolumn{2}{|c|}{ Gram Positive Bacteria } & \multicolumn{2}{|c|}{ Gram Negative Bacteria } & \multicolumn{4}{|l|}{ Fungi } \\
\hline & $S p$ & B s & $E$ c & $P a$ & Af & $S m$ & G $n$ & $\mathrm{Ca}$ \\
\hline 16 & $12.6 \pm 0.26$ & $14.3 \pm 0.27$ & $12.6 \pm 0.57$ & NA & $18.3 \pm 0.72$ & $20.3 \pm 0.72$ & $21.5 \pm 0.72$ & NA \\
\hline 17 & $16.3 \pm 0.72$ & $17.8 \pm 0.72$ & $15.2 \pm 0.72$ & NA & $15.4 \pm 0.63$ & $16.2 \pm 0.58$ & $22.1 \pm 0.72$ & NA \\
\hline 18 & $20.6 \pm 0.72$ & $23.8 \pm 0.72$ & $20.6 \pm 0.72$ & NA & $20.3 \pm 0.72$ & $21.3 \pm 0.52$ & $24.6 \pm 0.72$ & NA \\
\hline 19 & $20.4 \pm 0.72$ & $20.8 \pm 0.72$ & $17.6 \pm 0.72$ & NA & $20.3 \pm 0.58$ & $21.2 \pm 0.58$ & $22.1 \pm 0.58$ & NA \\
\hline 20 & $16.5 \pm 0.72$ & $18.7 \pm 0.72$ & $20.3 \pm 0.72$ & NA & $22.3 \pm 0.58$ & $24.9 \pm 0.58$ & $25.4 \pm 0.58$ & NA \\
\hline 21 & $19.8 \pm 0.72$ & $20.6 \pm 0.72$ & $21.3 \pm 0.72$ & NA & $21.7 \pm 0.58$ & $22.3 \pm 0.58$ & $22.6 \pm 0.58$ & NA \\
\hline 22 & $22.2 \pm 0.72$ & $23.8 \pm 0.72$ & $21.9 \pm 0.72$ & NA & $23.4 \pm 0.72$ & $25.3 \pm 0.52$ & $26.7 \pm 0.72$ & NA \\
\hline 23 & $19.3 \pm 0.72$ & $19.9 \pm 0.72$ & $16.3 \pm 0.72$ & NA & $18.2 \pm 0.72$ & $20.4 \pm 0.72$ & $21.3 \pm 0.72$ & NA \\
\hline 24 & $21.8 \pm 0.2$ & $23.8 \pm 0.58$ & $22.3 \pm 0.58$ & NA & $22.7 \pm 0.72$ & $23.7 \pm 0.72$ & $24.7 \pm 0.72$ & NA \\
\hline Amp & $23.8 \pm 0.2$ & $32.4 \pm 0.58$ & $\mathrm{nt}$ & nt & $\mathrm{nt}$ & $\mathrm{nt}$ & $\mathrm{nt}$ & $\mathrm{nt}$ \\
\hline Gent & - & - & $21.3 \pm 0.58$ & $17.3 \pm 0.63$ & $\mathrm{nt}$ & $\mathrm{nt}$ & $\mathrm{nt}$ & $\mathrm{nt}$ \\
\hline CF & $21.3 \pm 0.6$ & $22 . I \pm 0.5 I$ & $23.3 \pm 0.33$ & $22.6 \pm 0.54$ & $\mathrm{nt}$ & $\mathrm{nt}$ & nt & nt \\
\hline Amp.B & $\mathrm{Nt}$ & $\mathrm{Nt}$ & $\mathrm{nt}$ & $\mathrm{nt}$ & $23.7 \pm 0.63$ & $19.7 \pm 0.72$ & $28.7 \pm 0.58$ & $25.4 \pm 0.63$ \\
\hline
\end{tabular}

NA, no activity, SA, staphylococcus aureus; BS, bacillus subtilis; PA, pseudomonas aeuroginosa; EC, escherichia coli;AF, aspergillus fumigates; GC, Geotricum candidum; SR, Syncephalasteru mracemosum; CA, Candidaalbicans;AMP, ampicillin; Gent, gentamicin;Amp-B, amphotericin B; CF, ciprofloxacin, nt, not tested

Table 3 Antimicrobial activities of the tested standards and synthesized compounds as MICs $(\mu \mathrm{g} / \mathrm{mL})$.

\begin{tabular}{|c|c|c|c|c|c|c|c|c|}
\hline \multirow[b]{2}{*}{ Comp. } & \multicolumn{2}{|c|}{ GRAM positive bacteria } & \multicolumn{2}{|c|}{ Gram negative bacteria } & \multicolumn{2}{|c|}{ Fungi } & \multirow[b]{2}{*}{$G n$} & \multirow[b]{2}{*}{$\mathrm{Ca}$} \\
\hline & $S p$ & $B s$ & $E c$ & $\mathrm{~Pa}$ & Af & $S m$ & & \\
\hline 4 & 1.95 & 0.98 & 1.95 & NA & 3.9 & 1.95 & 0.98 & NA \\
\hline 14 & 0.49 & 0.24 & 0.98 & NA & 0.49 & 0.49 & 0.24 & NA \\
\hline 22 & 0.98 & 0.98 & 1.95 & NA & 0.98 & 0.49 & 0.49 & NA \\
\hline Amp & 0.98 & 0.24 & nt & nt & nt & nt & nt & $\mathrm{nt}$ \\
\hline Gent & nt & nt & 1.95 & 15.63 & nt & nt & nt & nt \\
\hline CF & 1.95 & 1.95 & 1.95 & 3.9 & nt & $\mathrm{nt}$ & nt & nt \\
\hline Amp. B & $\mathrm{nt}$ & nt & $\mathrm{nt}$ & $\mathrm{nt}$ & 0.98 & 3.9 & 0.24 & 0.49 \\
\hline
\end{tabular}

NA, no activity, SA, staphylococcus aureus; BS, bacillus subtilis; PA, pseudomonas aeuroginosa; EC, escherichia coli;AF, aspergillus fumigates; GC, Geotricum candidum; SR, Syncephalasteru mracemosum; CA, Candidaalbicans; AMP, ampicillin; Gent, gentamicin; Amp-B, amphotericin B; CF, ciprofloxacin, nt, not tested 


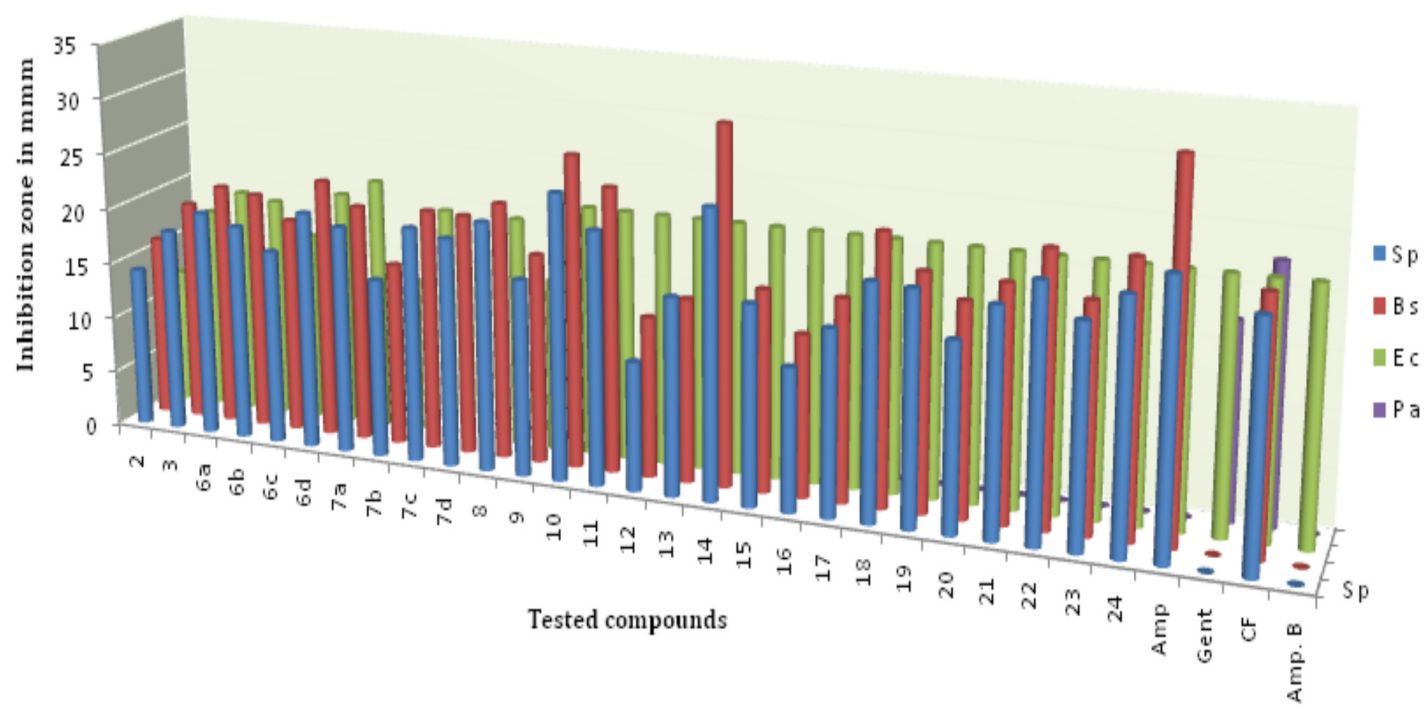

Figure 3 Antibacterial activities of compounds $\sigma_{b}-24$.

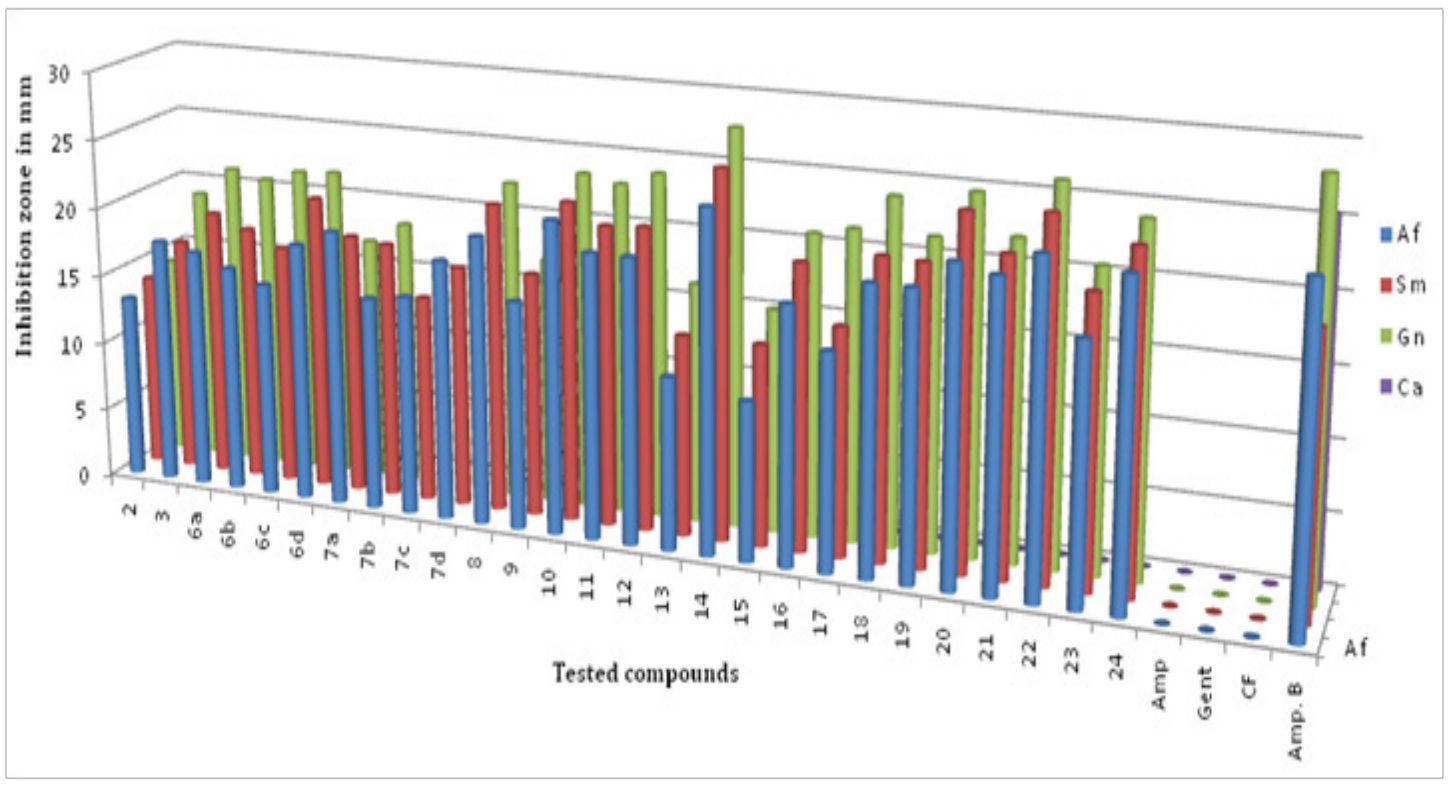

Figure 4 Antibacterial activities of the synthesized compounds.

\section{SAR}

The substitutions on position 3 of quinoline nucleus were more active than that on position 2. Scaffold containing heterocyclic bridge was more potent than that containing open chain bridge. Hydrazones were more active than imines. Nitrile groups were more potent than heterocyclic moieties. Oxazoles were more active than pyrazoles. Thioalkyl derivatives equipotent with $N$-phenyl thioacetanilide ones. Thioalkenes were more potent than short thioalkyl chains, and that were more potent than long thioalkyl ones. Electron withdrawing groups and para-substitutions of $\mathrm{N}$ - phenyl thioacetanilide derivatives were more potent than electron donatinging groups and orthosubstitutions respectively.

\section{Conclusion}

In the present work, we synthesized novel series of quinoline3-carbonitrile and 2-chloroquinoline derivatives. Screening for title compounds was carried for their potential antibacterial and antifungal activity. Most of the tested compounds revealed better activity against the Gram-positive rather than the Gram negative bacteria. All test compounds were found to be inactive against Pseudomonas aeuroginosa. Compounds 14, 10 and 22 exhibited excellent activity against Staphylococcus aureus, Bacillus subtilisand Escherichia coli compared with the standards drugs, while compounds 14, 22 and $\mathbf{6}_{\mathrm{d}}$ have strong antifungal activity against Aspergillus fumigatus, Syncephalasterum racemosum, Geotricum candidum, comparable to Amphotericin B. Finally, none of the synthesized compounds gave any activity against Candida albicans. Molecular docking study revealed that the synthesized compounds have potential antimicrobial activity and can be further optimized and developed as a lead compound.

\section{Acknowledgements}

Authors are thankful to the scientific research team of Regional 
Center of Mycology and Biotechnology, Faculty of Science, Al-Azhar University for providing laboratory facilities for biological activity.

\section{Conflict of interest}

The author declares no conflict of interest.

\section{References}

1. Saker L, Lee K, Cannito B, et al. Globalization and infectious diseases:a review of the linkages; 2004

2. Giske CG, Cornaglia G. ESCMID Study Group on Antimicrobial Resistance Surveillance (ESGARS) Supranational surveillance of antimicrobial resistance:The legacy of the last decade and proposals for the future. Drug Resistance Updates. 2010;13(4-5):93-98.

3. Legendre DP, Muzny CA, Marshall GD, et al. Antibiotic hypersensitivity reactions and approaches to desensitization. Clinical infectious diseases. 2013;58(8):1140-1148.

4. Garcia Rodriguez LA, Duque A, Castellsague J, et al. A cohort study on the risk of acute liver injury among users of ketoconazole and other antifungal drugs. British journal of clinical pharmacology. 1999;48(6):847852.

5. Eswaran S, Adhikari AV, Chowdhury IH, et al. New quinoline derivatives:Synthesis and investigation of antibacterial and anti tuberculosis properties. Eur J Med Chem. 2010;45(8):3374-3383.

6. Eswaran S, Adhikari AV, Shetty NS. Synthesis and antimicrobial activities of novel quinoline derivatives carrying 1, 2, 4-triazole moiety. European journal of medicinal chemistry. Eur $J$ Med Chem. 2009;44(11):4637-4647.

7. Narender P, Srinivas U, Ravinder M, et al. Synthesis of multi substituted quinolines from Baylis-Hillman adducts obtained from substituted 2-chloronicotinaldehydes and their antimicrobial activity. Bioorg Med Chem. 2006;14(13):4600-4609.

8. Gomez CM, Kouznetsov V. Recent developments on antimicrobial quinoline chemistry. Formatex. 2013

9. Sridhar R, Perumal PT, Etti S, et al. Design, synthesis and anti-microbial activity of 1H-pyrazole carboxylates. Bioorg Med Chem Lett. 2004;14(24):6035-6040.

10. Musad EA, Mohamed R, Saeed BA, et al. Synthesis and evaluation of antioxidant and antibacterial activities of new substituted bis $(1,3,4$ oxadiazoles), 3, 5-bis (substituted) pyrazoles and isoxazoles. Bioorganic \& medicinal chemistry letters. 2011;21(12):3536-3540.

11. Rai US, Isloor AM, Vijesh A, et al. Novel chromeno [2, 3-b]-pyrimidine derivatives as potential anti-microbial agents. European journal of medicinal chemistry. 2010;45(6):2695-2699.
12. Zhang Y, Jiang J, Chen Y. Synthesis and antimicrobial activity of polymeric guanidine and biguanidine salts. Polymer. 1999;40(22):6189-6198.

13. Kotb ER, El Hashash M, Salama MA, et al. Synthesis and reactions of some novel nicotinonitrile derivatives for anticancer and antimicrobial evaluation. Acta Chim Slov. 2009;56:908-919.

14. Vijesh AM, Isloor AM, Prabhu V, et al. Synthesis, characterization and anti-microbial studies of some novel 2, 4-disubstituted thiazoles. Eur $J$ Med Chem. 2010;45(11):5460-5464.

15. Sharma D, Narasimhan B, Kumar P, et al. Synthesis, antimicrobial and antiviral evaluation of substituted imidazole derivatives. European journal of medicinal chemistry. 2009;44(6):2347-2353.

16. Sridhar SK, Saravanan M, Ramesh A. Synthesis and antibacterial screening of hydrazones, Schiff and Mannich bases of isatin derivatives. $E u$ ropean Journal of Medicinal Chemistry. 2001;36(7-8):615-625.

17. Chaudhary P, Kumar R, Verma AK, et al. Synthesis and antimicrobial activity of $\mathrm{N}-$ alkyl and $\mathrm{N}$-aryl piperazine derivatives. Bioorganic \& medicinal chemistry. 2006;14(6):1819-1826.

18. Ammar Y, Saleh N, Micky J, et al. Activated nitriles in heterocyclic chemistry: Facile synthesis and antimicrobial activity of some pyrimidine, pyrazolopyrimidine and pyrazolotriazine derivatives containing sulfonamido moiety. Indian J Chem B. 2004;43:2203-2211.

19. Panneerselvam P, Nair RR, Vijayalakshmi G, et al. Synthesis of Schiff bases of 4-(4-aminophenyl)-morpholine as potential antimicrobial agents. Eur J Med Chem. 2005;40(2):225-229.

20. Bauernfeind A, Petermuller C. In vitro activity of ciprofloxacin, norfloxacin and nalidixic acid. European Journal of Clinical Microbiology. 1983;2(2):111-115.

21. Viegas Junior C, Danuello A, da Silva Bolzani V, et al. CA Molecular hybridization:a useful tool in the design of new drug prototypes. Current medicinal chemistry. 2007;14(17):1829-1852.

22. Sultana K, Najm ul Hassan Khan, Khadija Shahid. Efficient solvent free synthesis and $\mathrm{X}$ ray crystal structure of some cyclic moieties containing N-aryl imide and amide. Middle-East Journal of Scientific Research. 2013;18(4):438-443.

23. Srivastava RP, Bhaduri AP. Synthetic applications of 2-chloro-3-formylquinoline. Journal of heterocyclic chemistry. 1987;24(1):219-222.

24. Bonev B, Hooper J, Parisot J. Principles of assessing bacterial susceptibility to antibiotics using the agar diffusion method. Journal of antimicrobial chemotherapy. 2008;61(6):1295-1301.

25. Wiegand I, Hilpert K, Hancock RE. Agar and broth dilution methods to determine the minimal inhibitory concentration (MIC) of antimicrobial substances. Nature protocols. 2008;3(2):163-175. 